\title{
Effect of Polymer Structure on Gas Transport Properties of Selected Aromatic Polyimides, Polyamides and TR Polymers
}

\author{
Zachary P. Smith, ${ }^{1}$ Guiomar Hernández, ${ }^{2}$ Kristofer L. \\ Gleason, ${ }^{1}$ Advaith Anand, ${ }^{1}$ Cara M. Doherty ${ }^{3}$ Kristina \\ Konstas, ${ }^{3}$ Cristina Alvarez, ${ }^{2}$ Anita J. Hill, ${ }^{3}$ Angel E. Lozano, ${ }^{2}$ \\ Donald R. Paul, ${ }^{1}$ Benny D. Freeman ${ }^{1^{*}}$
}

1. Department of Chemical Engineering, Texas Materials Institute, Center for Energy and Environmental Research, The University of Texas at Austin, 10100 Burnet Road, Bldg. 133, Austin, TX 78758, USA

2. Departamento de Química Macromolecular Aplicada, Instituto de Ciencia y Tecnología de Polímeros, CSIC, Juan de la Cierva 3, 28006 Madrid, Spain

3. Commonwealth Scientific and Industrial Research Organization (CSIRO), Manufacturing, Private Bag 10, Clayton South 3169, Victoria, Australia

Submission to Journal of Membrane Science

June 12, 2015

* Corresponding Author: e-mail: freeman@che.utexas.edu $\quad$ Tel: +1(512)232-2803 


\section{Graphical Abstract}
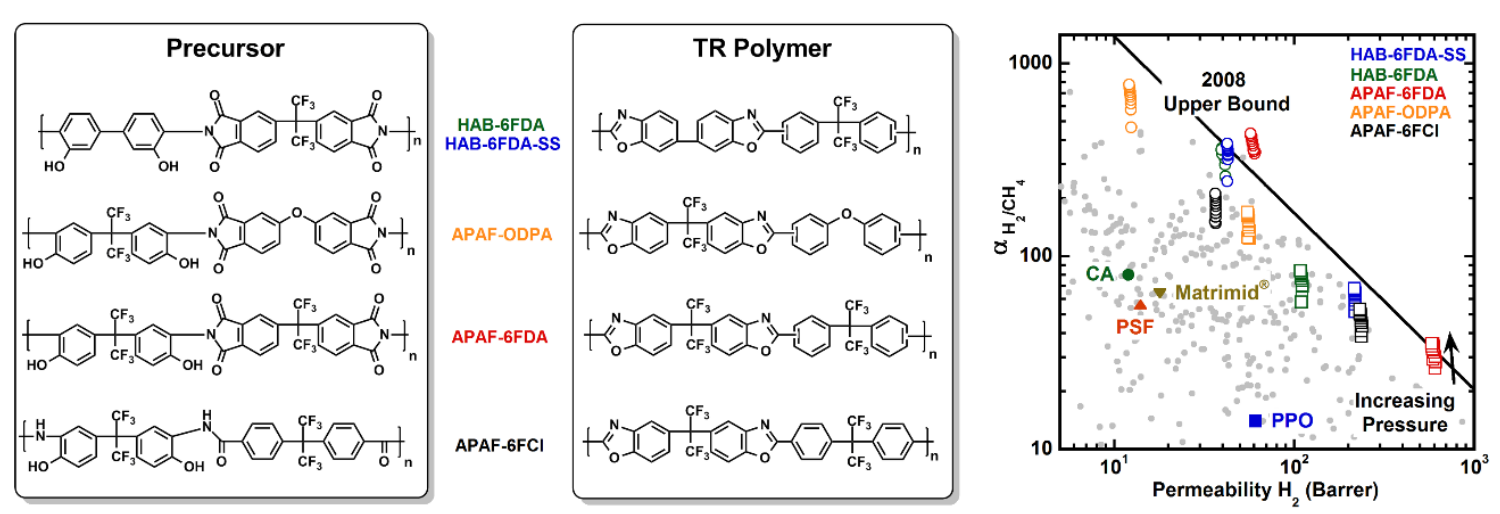

22

23

24

25

26 
hydroxyphenyl)-hexafluoropropane (APAF) and 6FDA. With the exception of HAB6FDA polyimides, pure-gas $\mathrm{CO}_{2}$ feed pressures up to approximately 50 bar do not reveal a plasticization pressure point, but conditioning effects are observed for most samples. APAF-6FDA TR polymers have pure-gas permeabilities and selectivities beyond the propylene/propane upper bound.

Keywords: Thermally rearranged polymers; Polybenzoxazoles; $\mathrm{CO}_{2}$ separations; Olefin/paraffin separations; Plasticization 


\section{INTRODUCTION}

Polymer membranes are currently deployed for applications such as natural gas sweetening, nitrogen enrichment, and syngas ratio adjustment. ${ }^{1}$ To improve separation performance, new materials are sought with higher gas throughput, improved selectivity, and chemical/thermal resistance to aggressive feed conditions. Polybenzoxazoles (PBOs) and related structures have recently attracted significant interest from the membrane community, and these polymers are of interest for this work.

In 2007, Park et al. reported a method for synthesizing polymer films of PBO, polybenzothiazole, and polybenzimidazole structures. ${ }^{2}$ These polymer films were formed from a solid-state reaction of polyimide precursors containing nucleophilic functional groups ortho-position to their diamine monomer. Although the technical nomenclature for this type of reaction is a 'condensation reaction', whereby 2 molecules of $\mathrm{CO}_{2}$ are evolved per repeat unit, ${ }^{3}$ due to the thermal processing requirements needed to form these polymers, they are referred to as so-called 'thermally rearranged', or TR polymers.

Several synthetic design parameters can be used to modify the transport properties of these polymers. Han et al. investigated differences in the transport properties of TR polymers based on the synthesis route of their polyimide precursors. ${ }^{4}$ Calle et al. and Guo et al. demonstrated that the onset temperature for thermal rearrangement correlates with the glass transition temperature of the polyimide. ${ }^{5-7}$ Guo et al. and Sanders et al. demonstrated that transport properties could further be tuned by modifying the size of the ortho-functional leaving group, which, in addition to $\mathrm{CO}_{2}$, is also evolved during thermal rearrangement. ${ }^{8-10}$

The thrust of this paper is to extend the current understanding of gas separations with TR polymers by investigating several polymer backbone chemistries. In this regard, we have investigated three poly(hydroxyimide) precursors synthesized via thermal 
imidization in solution and their corresponding TR polymers. These polymers were selected due to their relevance in the field of polymer membrane research. 6FDA-based polyimides have been of interest for gas separations for years, ${ }^{11-13}$ and analogous structures have been pursued for TR polymers..$^{2,3,14-16}$ Ether-linkages, such as those found in polysulfones and polyamides, show a higher degree of rotational freedom, ${ }^{17,18}$ so the effect of these linkages on the thermal rearrangement reaction and transport properties were also investigated. In addition to light gas and $\mathrm{CO}_{2}$ permeability measurements, ${ }^{2}$ ether functionalities have also been investigated in TR polymers with dynamic mechanical analysis ${ }^{19}$ and for aromatic/aliphatic separations. ${ }^{20}$ HAB and APAF-based TR polymers have shown promising transport properties for separating light gases and $\mathrm{CO}_{2},{ }^{2,3,15,16,21}$ and related structures have been fabricated into hollow-fibers and tested as thin films in physical aging studies. ${ }^{22-24}$

For separations involving $\mathrm{CO}_{2}$ and other condensable penetrants, such as propylene and propane, plasticization can affect membrane performance. ${ }^{25,26}$ Polyimides are often susceptible to plasticization effects, and crosslinking strategies have been suggested to increase plasticization resistance. ${ }^{27-29}$ These strategies often result in polymers with higher selectivities but lower permeabilities. ${ }^{30,31}$ Conversely, for TR polymers, thermal treatment of polyimides typically results in higher permeabilities and lower selectivities. ${ }^{2}$ Similar to crosslinking, however, TR polymers show improved plasticization resistance. ${ }^{2,32}$ This study investigates resistance to $\mathrm{CO}_{2}$ plasticization through hysteresis pressurization-depressurization loops for a series of polyimides, polyamides, and TR polymers.

Olefin/paraffin separations have been identified as an emerging application for membrane-based separations, ${ }^{1}$ and some of the best performing polymers are 6FDAbased polyimides. ${ }^{26,33,34}$ To investigate the performance of TR polymers with related 
structures, this study evaluates pure-gas permeability of $\mathrm{C}_{2} \mathrm{H}_{4}, \mathrm{C}_{2} \mathrm{H}_{6}, \mathrm{C}_{3} \mathrm{H}_{6}$, and $\mathrm{C}_{3} \mathrm{H}_{8}$ for one TR polymer, based on APAF-6FDA, and results show $\mathrm{C}_{3} \mathrm{H}_{6} / \mathrm{C}_{3} \mathrm{H}_{8}$ performance that is beyond the polymer upper bound.

\section{Materials ANd Methods}

\section{Polyimide and polyamide synthesis}

Several polyimides and a polyamide were synthesized for this study. Diamines included 3,3'-dihydroxy-4,4'-diamino-biphenyl (HAB) and 2,2-bis (3-amino-4hydroxyphenyl)-hexafluoropropane (APAF); dianhydrides included 2,2'-bis-(3,4dicarboxyphenyl) hexafluoropropane dianhydride (6FDA) and 4,4'-oxydiphthalic anhydride (ODPA); the diacid chloride was 2,2'-bis(4-chlorocarbonyl phenyl) hexafluoropropane $(6 \mathrm{FCl})$. The chemically imidized polyimide, HAB-6FDA-C, was synthesized according to a method described previously. ${ }^{16,35}$ HAB was supplied by Wakayama Seiko Kogyo Co., Ltd. (CAS \# 2373-98-0), 6FDA was purchased from Sigma Aldrich (CAS \# 1107-00-2), and APAF (CAS \# 83558-87-6) and ODPA (CAS \# 182359-2) were purchased from Chriskev and Tokyo Chemical Industry (TCI), respectively. The thermally imidized APAF-6FDA polyimide and APAF-6FCl polyamide were synthesized as described previously. ${ }^{36}$ In addition to these samples, two additional polyimides were thermally imidized in solution (i.e., HAB-6FDA and APAF-ODPA), and one polyimide was synthesized via thermal imidization in the solid-state (i.e., HAB6FDA-SS). Unless otherwise noted, all concentration percentages for polymer solutions are reported as the total mass of monomer in $\mathrm{g}$ per total volume of solvent in $\mathrm{mL}$. 


\section{Thermal imidization in solution for $\mathrm{HAB}-6 \mathrm{FD} A$ and $A P A F-O D P A$}

Standard solution thermal imidization techniques were used to prepare HAB6FDA and APAF-ODPA. ${ }^{37,38}$ To prepare the monomers for synthesis, HAB and APAF were placed in a vacuum oven, which was shielded from light, and dried under full vacuum for $12 \mathrm{~h}$ at $60^{\circ} \mathrm{C}$ and $120^{\circ} \mathrm{C}$, respectively. The dianhydrides were prepared using a two-step process. First, 6FDA and ODPA were held at $200^{\circ} \mathrm{C}$ under -10 in $\mathrm{Hg}$ for $6 \mathrm{~h}$ to dry the monomers and to close any hydrolyzed rings in the dianhydrides. Second, the oven temperature was lowered to $120^{\circ} \mathrm{C}$ and held for $12 \mathrm{~h}$ under full vacuum.

All monomers were allowed to cool to room temperature under full vacuum before beginning synthesis. Reactions were performed in a three-neck flask with an overhead mechanical stirrer. Synthesis glassware and Teflon ${ }^{\circledR}$ stirring blades were kept in a drying oven at approximately $115^{\circ} \mathrm{C}$ for $24 \mathrm{~h}$ before use. Ultra-high purity nitrogen gas (Airgas, 99.999\%) was flowed through a Drierite column (W.A. Hammond Drierite Co., Ltd., Xenia, OH) to minimize the presence of water vapor in the reaction vessel.

In a typical synthesis batch, $25 \mathrm{mmol}$ of diamine was added to the reaction flask. The diamines were dissolved in anhydrous N-methyl-2-pyrrolidone (NMP, SigmaAldrich, $\mathrm{P} / \mathrm{N}$ 328634). HAB was dissolved in approximately $55 \mathrm{~mL}$ of NMP, and APAF was dissolved in approximately $51 \mathrm{~mL}$ of NMP. The diamines were allowed to dissolve for approximately $1 \mathrm{~h}$, and an ice bath was used to cool the reaction solution before adding the dianhydrides. To the reaction flask containing HAB, $25 \mathrm{mmol}$ of 6FDA were slowly added before adding an additional $55 \mathrm{~mL}$ of NMP. For the reaction flask containing APAF, $25 \mathrm{mmol}$ of ODPA were slowly added before adding an additional 51 $\mathrm{mL}$ of NMP. Therefore, the solids concentration in the HAB-6FDA solution was $15 \%$, and that in the APAF-ODPA solution was 20\%. The reaction proceeded for approximately $18 \mathrm{~h}$. 
To begin thermal imidization, additional anhydrous NMP and an azeotropic agent, 1,2-dichlorobenzene (Sigma Aldrich, P/N 240664), were added to the reaction flask. To the HAB-6FDA poly(amic acid), approximately $55 \mathrm{~mL}$ of NMP and $41 \mathrm{~mL}$ of 1,2dichlorobenzene were added to make an $8 \%$ solution, where a 1:4 volumetric ratio was maintained for 1,2-dichlorobenzene to NMP. A 10\% solution was used for APAFODPA. A Dean Stark trap and condenser was attached to the nitrogen outlet of the reaction flasks, and the poly(amic acid)s were imidized at $180^{\circ} \mathrm{C}$ for $24 \mathrm{~h}$.

Following imidization, the polymer solutions were cooled, further diluted with NMP to decrease solution viscosity, and precipitated in a non-solvent. HAB-6FDA was diluted to a 5\% solution, and APAF-ODPA was diluted to an $8 \%$ solution. For HAB6FDA, the non-solvent was methanol (VWR, P/N BDH-1135), and for APAF-ODPA, the non-solvent was an 85:15 mixture of methanol:deionized water. Approximately $10 \mathrm{~mL}$ of polymer solution was precipitated in approximately $400 \mathrm{~mL}$ aliquots of non-solvent, which were left stirring on low speeds in a blender. The polymer fibers were filtered from the solution using a Büchner funnel and washed with the non-solvent mixture.

Reaction solvent was initially removed by solvent extraction. HAB-6FDA was left stirring in approximately $1.5 \mathrm{~L}$ of methanol, and APAF-ODPA was left stirring in 1.5 L of a 20:80 mixture of methanol:deionized water for approximately $24 \mathrm{~h}$. The polymers were then dried by filtration, rinsed thoroughly with their extraction solvent, and placed in fresh batches of extraction solvent. After waiting an additional $24 \mathrm{~h}$, the polymers were again filtered and rinsed and placed in evaporation dishes before being transferred to a vacuum oven. Samples were dried in the vacuum oven at $80^{\circ} \mathrm{C}$ for $24 \mathrm{~h}, 120^{\circ} \mathrm{C}$ for $24 \mathrm{~h}$, and $200^{\circ} \mathrm{C}$ for $48 \mathrm{~h}$. Complete removal of solvent was confirmed by thermogravimetric analysis (TGA). 


\section{Thermal imidization in the solid-state for $\mathrm{HAB}-6 \mathrm{FD} A$}

HAB-6FDA was also prepared via thermal imidization in the solid state. The label, -SS, will be used to designate this type of imidization. For this synthesis method, the HAB-6FDA poly(amic acid) was prepared identically to the method described in the preceding section. However, instead of imidizing the poly(amic acid) in solution, the poly(amic acid) solution was diluted to $10 \%$ with NMP and poured onto flat glass plates. The glass plates were placed in a vacuum oven and heated under a light vacuum of approximately -10 in $\mathrm{Hg}$ at $60^{\circ} \mathrm{C}, 100^{\circ} \mathrm{C}$, and $150^{\circ} \mathrm{C}$ for $1 \mathrm{~h}, 1.5 \mathrm{~h}$, and $1.5 \mathrm{~h}$, respectively. Next, the temperature was increased to $200^{\circ} \mathrm{C}$ for $1.5 \mathrm{~h}$ and $250^{\circ} \mathrm{C}$ for $1.5 \mathrm{~h}$ while applying full vacuum. Residual solvent was removed from the HAB-6FDA-SS films by heating at approximately $270^{\circ} \mathrm{C}$ for $12 \mathrm{~h}$ under full vacuum. Solvent removal was confirmed by TGA.

\section{Film Casting}

For the chemically imidized polyimide (i.e., HAB-6FDA-C), films were cast according to a procedure described previously. ${ }^{16}$ All solution thermallyimidized/amidized films (i.e., HAB-6FDA, APAF-6FDA, APAF-6FCl, and APAFODPA) were cast as described previously. ${ }^{36}$ APAF-6FDA, APAF-6FCl, and APAFODPA were cast from 2\% solutions of N,N-dimethylacetimide (DMAc, Sigma Aldrich, P/N D137510), and HAB-6FDA, which was more difficult to filter, was cast from a $1 \%$ solution. HAB-6FDA-SS was prepared as a film according to the method described in the previous section. All samples were approximately $30-40 \mu \mathrm{m}$ in thickness except for the APAF-ODPA sample, which was approximately $20 \mu \mathrm{m}$. APAF-ODPA had the lowest permeability of all of the samples, and a thinner film was needed to more accurately determine permeability. 


\section{TR Polymer Formation}

TR polymers were formed via a solid-state reaction of polyimide and polyamide films. All thermally imidized samples (i.e., HAB-6FDA, HAB-6FDA-SS, APAF-6FDA, and APAF-ODPA) were treated according to the following heating protocol. Polymer films were placed onto a flat ceramic boat and were covered by a ceramic plate. To allow for nitrogen to flow across the sample but to prevent the samples from curling during thermal treatment, the plate was separated from the boat by approximately $1 \mathrm{~mm}$ thick metal spacers. The sample was placed into a Carbolite three zone hinged tube furnace (Model HZS 12/-/600, Watertown, Wisconsin, USA), and a nitrogen (Airgas, 99.999\%) flowrate of $900 \mathrm{~mL} / \mathrm{min}$ was applied across the furnace tube. The samples were heated to $300^{\circ} \mathrm{C}$ at a rate of $5^{\circ} \mathrm{C} / \mathrm{min}$, held for $1 \mathrm{~h}$, and then heated to $450^{\circ} \mathrm{C}$ at a rate of $5^{\circ} \mathrm{C} / \mathrm{min}$ and held for $30 \mathrm{~min}$. Next, the samples were cooled at a rate not to exceed $10^{\circ} \mathrm{C} / \mathrm{min}$. For the TR polymer formed from the polyamide (i.e., APAF-6FCl), the sample was heated at $5^{\circ} \mathrm{C} / \mathrm{min}$ from ambient temperature to $350^{\circ} \mathrm{C}$ and held for $1 \mathrm{~h}$, followed by cooling at a rate not to exceed $10^{\circ} \mathrm{C} / \mathrm{min}$.

\section{Characterization}

Thermogravimetric analysis (TGA) was used to study the thermal reactivity and thermal stability of polyimide and polyamide films using a TA Instruments Q500 TGA (TA Instruments, New Castle, DE, USA). Samples were heated under ultra-high purity $\mathrm{N}_{2}$ (Airgas, 99.999\%) with a balance flowrate of $40 \mathrm{~mL} / \mathrm{min}$ and a sample flowrate of 60 $\mathrm{mL} / \mathrm{min}$. TGA thermograms were used to analyze the relative thermal reactivity and stability of films by heating at $5^{\circ} \mathrm{C} / \mathrm{min}$ from ambient temperature to $800^{\circ} \mathrm{C}$ and monitoring the total mass loss and the derivative mass loss. The experimental mass loss during thermal rearrangement was also determined with TGA by following the same thermal treatment protocol used in the tube furnace, but with one exception: the cooling 
rate for the TGA, which could be more accurately controlled than the furnace, was maintained at exactly $10^{\circ} \mathrm{C} / \mathrm{min}$.

Gel fractions were determined using a Soxhlet extractor (Wilmad-LabGlass, LG6900-100) with DMAc (Sigma Aldrich, P/N D137510) as a solvent. Samples were weighed, placed into the extractor, and then refluxed in DMAc for 3 days or until the sample was fully dissolved. Next, samples were dried for $12 \mathrm{~h}$ at $225^{\circ} \mathrm{C}$ to remove solvent and the remaining portion of sample was weighed again. Gel fraction is reported as the final mass of polymer after solvent exposure divided by the initial mass of polymer.

Molecular weight was determined using size exclusion chromatography (SEC). This system consisted of a differential refractometer detector (VE 3580 RI detector, Viscotek), a differential viscometer, and right angle light scattering (RALS) detector (Trisec Model 270, Dual Detector, Viscotek), as described previously. ${ }^{36}$

Solution ${ }^{1} \mathrm{H}$ and ${ }^{13} \mathrm{C}$ NMR was performed with a Varian Inova $500 \mathrm{MHz}$ NMR. Samples were dissolved in DMSO (Cambridge Isotope, P/N DLM-10-10) at concentrations of approximately $3 \%$ by weight. Peak assignments were determined from the following 2-D NMR experiments: correlation spectroscopy (COSY), heteronuclear single quantum correlation (HSQC) spectroscopy, and heteronuclear multiple bond correlation (HMBC) spectroscopy, similar to a method described previously. ${ }^{36}$

Permeability was determined at $35^{\circ} \mathrm{C}$ using a constant volume variable pressure apparatus. $^{39,40}$ Pure-gas permeability was calculated according to Equation (1):

$$
P_{i}=\frac{V_{D} l}{p_{2} A R T}\left[\left(\frac{d p_{1}}{d t}\right)_{s s}-\left(\frac{d p_{1}}{d t}\right)_{\text {leak }}\right]
$$


where $P_{i}$ is the permeability of component $i, V_{D}$ is the calibrated volume downstream of the polymer film, $l$ is the film thickness, $p_{2}$ is the upstream pressure, $A$ is the area of the film accessible to gas permeation, $R$ is the ideal gas constant, $T$ is the absolute experimental temperature, $\left(\frac{d p_{1}}{d t}\right)_{s s}$ is the steady state rate of pressure-rise, and $\left(\frac{d p_{1}}{d t}\right)_{\text {leak }}$ is the system leak rate. For $\mathrm{C}_{2} \mathrm{H}_{4}, \mathrm{C}_{2} \mathrm{H}_{6}, \mathrm{C}_{3} \mathrm{H}_{6}$, and $\mathrm{C}_{3} \mathrm{H}_{8}$, upstream fugacity values, $\mathrm{f}_{2}$, were used instead of upstream pressure values, $\mathrm{p}_{2}$, to calculate permeabilities. Fugacities were calculated using second and third virial coefficients from Dymond et al., and gas density data was taken from a NIST database, REFPROP. ${ }^{41,42}$ Third virial coefficients were estimated by fitting a polynomial to multiple data points around the temperature range of interest (e.g., $35^{\circ} \mathrm{C}$ ) and taking the best fit value. Saturation fugacities were estimated by calculating fugacities at the saturation pressure. For supercritical gases, saturation pressures were determined by extrapolating vapor-pressure curves of $\ln p_{\text {sat }}$ versus $1 / \mathrm{T}$ to $35^{\circ} \mathrm{C} .^{43}$ In certain cases where pressure-based permeabilities are reported, there are significant differences between the values of pressure and fugacity. For example, at the highest pressure considered (i.e., 50 bar), $\mathrm{CO}_{2}$ has a fugacity of $39.2 \mathrm{bar}$, and $\mathrm{CH}_{4}$ has a fugacity of 46.4 bar. While these differences do have an effect on permeability values calculated based on fugacity, there were no differences in the qualitative trends for our data, including $\mathrm{CO}_{2}$ plasticization pressure curves. Pure-gas selectivity values were calculated as the ratio of the pure-gas permeabilities. The permeabilities used in the selectivity calculations were based on pressure for $\mathrm{H}_{2}, \mathrm{~N}_{2}, \mathrm{O}_{2}$, $\mathrm{CH}_{4}$, and $\mathrm{CO}_{2}$, and they were based on fugacity for $\mathrm{C}_{2} \mathrm{H}_{4}, \mathrm{C}_{2} \mathrm{H}_{6}, \mathrm{C}_{3} \mathrm{H}_{6}$, and $\mathrm{C}_{3} \mathrm{H}_{8}$.

For $\mathrm{H}_{2}, \mathrm{~N}_{2}, \mathrm{O}_{2}, \mathrm{CH}_{4}$, and $\mathrm{CO}_{2}$, samples were tested at a pressure of approximately 1 bar, and then from 5 bar to 50 bar in increments of 5 bar. For the HAB-6FDA polyimide, the permeability of $\mathrm{N}_{2}$ and $\mathrm{CH}_{4}$ at 1 bar was close to the sample leak rate, and 
these points were discarded. All gases were allowed to permeate for at least 6 times the time lag before recording the permeation data. For $\mathrm{CO}_{2}$, the time lag was estimated at 1 bar, and each pressure step was run for 6 times the time lag at 1 bar. Because the initial pressurization step took several seconds to reach the set point at the upstream pressure, diffusion coefficients determined from these time-lag measurements showed significant test-to-test variability. Therefore, we cannot report diffusion coefficients for $\mathrm{CO}_{2}$. The time-lag for the APAF-6FDA TR polymer was too fast to estimate, so this sample was held for $6 \mathrm{~min}$ at each pressure. Hysteresis loops for $\mathrm{CO}_{2}$ were run using the aforementioned pressure steps, followed by decreasing the upstream pressure in increments of 5 bar down to a pressure of 5 bar. Following this hysteresis loop, the sample was then held under vacuum for approximately 25 time-lags, and a second pressurization step was performed using a protocol identical to that of the first pressurization step.

For $\mathrm{C}_{2} \mathrm{H}_{4}, \mathrm{C}_{2} \mathrm{H}_{6}, \mathrm{C}_{3} \mathrm{H}_{6}$, and $\mathrm{C}_{3} \mathrm{H}_{8}$, different pressurization steps were used according to the activity of the gases, where activity is defined as the ratio between the experimental upstream fugacity and the saturation fugacity (i.e., $\left.f / f_{\text {sat }}\right)$. The time-lag for these samples was determined at an activity of 0.05 , and the sample was subsequently pressurized by incrementally increasing the upstream activities by 0.05 . For $\mathrm{C}_{2} \mathrm{H}_{4}, \mathrm{C}_{2} \mathrm{H}_{6}$, $\mathrm{C}_{3} \mathrm{H}_{6}$, and $\mathrm{C}_{3} \mathrm{H}_{8}$, the maximum activities that could be reached with our systems were approximately $0.90,0.95,0.80$, and 0.75 , respectively. For samples that went through a plasticization pressure, comparisons of sample permeability and selectivity to the upper bound were only made up to the plasticization pressure except for olefin/paraffin datasets, where the entire pressure range is considered.

Positron annihilation lifetime spectroscopy (PALS) was used to compare differences in free volume between samples. Similar to our previous study, ${ }^{36}$ we fitted 
the PALS data to three lifetimes, indicating the presence of a single free volume distribution. For the TR polymers in this study, bimodal distributions could also be fit using four lifetimes, but, despite adding an additional fitting parameter, similar parameter uncertainties were obtained when fitting data to three or four lifetimes (single or bimodal distributions). Initial lifetimes and intensities were fit using a computer program, LT9, ${ }^{44}$ and these parameters were used as initial fitting parameters for determining free volume distributions with another computer program, PAScual. ${ }^{45}$ Very low intensities were recorded for some of the polyimide samples and partially converted TR polymers, which potentially indicates ortho-positronium (o-Ps) inhibition due to carbonyl functionality in the imides considered in this study. ${ }^{36,46}$ Therefore, we do not report PALS intensities for our samples; instead, we compare free volume using a semiemperical model: ${ }^{47-50}$

$$
\tau_{3}=\frac{1}{2}\left[1-\frac{R_{F}}{R_{F}+\Delta R}+\frac{1}{2 \pi} \sin \left(\frac{2 \pi R_{F}}{R_{F}+\Delta R}\right)\right]^{-1}
$$

where $\tau_{3}$ is the $o$-Ps lifetime, $R_{F}$ is the radius of the free volume element, and $\Delta R$ is the electron layer thickness $(1.66 \AA){ }^{48,51}$ The volume of a hypothetical, spherical free volume element, $V_{F}$, can then be estimated from $R_{F}: 52$

$$
V_{F}=\frac{4}{3} \pi\left(R_{F}\right)^{3}
$$




\section{RESULTS AND DisCUSSION \\ Overview of polyimides, polyamide, and TR polymers considered in this study relative to other materials reported in the literature}

Chemical structures of the polymers considered in this study are presented in Table 1. These structures are drawn as linear polymers, but, in reality, these structures may contain some degree of crosslinking. Sanders et al. and Smith et al. studied the permeability, diffusivity, and solubility of the HAB-6FDA-C polyimide and its corresponding TR polymers and found that the process of thermal rearrangement more strongly increases diffusivity than solubility. ${ }^{15,16,35}$ Guo et al. and Sanders et al. studied acetate and hydroxyl functional HAB-6FDA polyimides and TR polymers, among others, and found that gas permeability is more strongly influenced by the size of the orthofunctional leaving group than by the method in which these polymers were synthesized..$^{8-}$

${ }^{10}$ Park et al. reported $\mathrm{H}_{2}, \mathrm{~N}_{2}, \mathrm{O}_{2}, \mathrm{CH}_{4}$ and $\mathrm{CO}_{2}$ permeabilities for a number of solid-state imidized polyimides and their corresponding TR polymers. ${ }^{2,3}$ These samples include an APAF-6FDA-SS polyimide, several APAF-6FDA-SS TR polymers treated for $1 \mathrm{~h}$ at temperatures between $350^{\circ} \mathrm{C}$ and $450^{\circ} \mathrm{C}$, and an APAF-ODPA-SS TR polymer treated for $1 \mathrm{~h}$ at $450^{\circ} \mathrm{C} .^{2,3}$ Han et al. extended this work by investigating the effect of synthesis route on transport properties for APAF-6FDA polyimides and their corresponding TR polymers. ${ }^{4}$ These experiments were performed for polyimides synthesized from thermal imidization in the solid-state, thermal imidization in solution, and two forms of chemical imidization: chemical imidization with silylation and chemical imidization without silylation. ${ }^{4}$ Additional work by Han et al. has shown $\mathrm{H}_{2}$ and $\mathrm{CO}_{2}$ permeation results over a range of temperatures for the APAF- $6 \mathrm{FCl}$ polyamide and corresponding TR polymer. ${ }^{21}$

Permeation and characterization data for the HAB-6FDA-C polyimide and TR polymers converted at temperatures between $350^{\circ} \mathrm{C}$ and $450^{\circ} \mathrm{C}$ have been reported in our previous studies. ${ }^{15}$ Herein, an additional four polyimides (i.e., HAB-6FDA-SS, HAB- 
6FDA, APAF-ODPA, APAF-6FDA), a polyamide (APAF-6FCl), and their corresponding TR polymers are considered. 


APAF-ODPA

Table 1. List of polyimides, polyamide, and TR polymers considered. Reaction temperatures and reaction products are included in the table. HAB-6FDA-C was thermally treated at $350^{\circ} \mathrm{C}$ for $1 \mathrm{~h}, 400^{\circ} \mathrm{C}$ for $1 \mathrm{~h}$, or $450^{\circ} \mathrm{C}$ for $30 \mathrm{~min}$ according to our previous work. ${ }^{15,16}$ The HAB-6FDA-SS, HAB-6FDA, APAF-ODPA, and APAF-6FDA samples were treated at $450^{\circ} \mathrm{C}$ for $30 \mathrm{~min}$, and the APAF- $6 \mathrm{FCl}$ sample was treated at $350^{\circ} \mathrm{C}$ for $1 \mathrm{~h}$. 


\subsubsection{Thermal reactivity of polyimides and the polyamide}

Table 2 presents the glass transition temperatures $\left(T_{\mathrm{g}}\right)$, theoretical mass loss expected from stoichiometric conversion of the polyimide to its TR polymer, and actual mass loss of samples considered. All samples have near-quantitative or slightly above quantitative conversion to their TR polymer structure. The uncertainty in these experiments is approximately $\pm 0.1 \%$. Thus, mass loss beyond that expected from stoichiometric conversion is likely associated with some thermal degradation.

For the thermally imidized poly(hydroxyimide)s, changes in $\mathrm{T}_{\mathrm{g}}$ track with the difference between the actual mass loss and the theoretical mass loss. The glass transition temperature increases in the following order: APAF-ODPA $<$ APAF-6FDA $<$ HAB-6FDA. Correspondingly, the sample with the highest $T_{g}$ (i.e., HAB-6FDA), loses $0.4 \%$ more mass than theoretically expected, and the sample with the lowest $\mathrm{T}_{\mathrm{g}}$ (i.e., APAF-ODPA), loses $0.9 \%$ more mass than theoretically expected. Calle et al. and Guo et al. have correlated the onset of thermal rearrangement with $\mathrm{T}_{\mathrm{g}}$ for a variety of polyimides, ${ }^{5,6}$ and our findings support this interpretation of the thermal rearrangement reaction occurring at lower temperatures for samples with lower $T_{g} s$.

Table 2 also presents data for HAB-6FDA/-C/-SS and the other samples in this study. HAB-6FDA and HAB-6FDA-SS TR polymers have similar, near-quantitative mass loss. Sanders et al. have shown that conversion and permeation properties are similar between samples of identical chemical structure but prepared through different synthesis routes. ${ }^{10}$ Our results support the same conclusion. However, for HAB-6FDA$\mathrm{C}$, which contains an acetate-functional group, samples converted under the same conditions as the hydroxyl-functional HAB-6FDA polymers (i.e., $450^{\circ} \mathrm{C}$ and $30 \mathrm{~min}$ ), showed a lower mass loss, indicating lower thermal reactivity for acetate-functional 


\begin{tabular}{|c|c|c|c|c|c|c|c|}
\hline Sample & $\begin{array}{c}\mathrm{T}_{\mathrm{g}} \\
\left({ }^{\circ} \mathrm{C}\right)\end{array}$ & $\begin{array}{c}\text { Rearrangement } \\
\text { Temperature } \\
\left({ }^{\circ} \mathrm{C}\right)\end{array}$ & $\begin{array}{c}\text { Rearrangement } \\
\text { Time (min) }\end{array}$ & $\begin{array}{c}\text { Theoretical } \\
\text { Mass Loss } \\
(\%)\end{array}$ & $\begin{array}{c}\text { Theoretical } \\
\text { Actual Mass } \\
\text { Loss (\%) }\end{array}$ & $\begin{array}{c}\text { Mass Loss } \\
\text { Minus Actual } \\
\text { Mass Loss (\%) }\end{array}$ & Reference \\
\hline HAB-6FDA-C & $255^{16}$ & $350,400,450$ & $60,60,30$ & 24.3 & $9.5,14.6,18.5$ & NA & 16 \\
\hline HAB-6FDA-SS & -- & 450 & 30 & 14.1 & 14.6 & 0.5 & This Study \\
\hline HAB-6FDA & $314^{6}$ & 450 & 30 & 14.1 & 14.5 & 0.4 & 6 \\
\hline APAF-ODPA & $266^{6}$ & 450 & 30 & 13.7 & 14.6 & 0.9 & 6 \\
\hline APAF-6FDA & $303^{6}$ & 450 & 30 & 11.4 & 12.2 & 0.8 & 6 \\
\hline APAF-6FCl & $258^{54}$ & 350 & 60 & 5.0 & 5.3 & 0.3 & 6 \\
\hline
\end{tabular}

Table 2. Glass transition temperatures for polyimide and polyamide precursors, conversion conditions, theoretical mass loss, actual mass loss, and the difference between the theoretical and actual mass loss of samples upon thermal rearrangement. No $T_{g}$ was detected for HAB-6FDA-SS. ${ }^{\dagger}$ The heating rate was set at $5^{\circ} \mathrm{C} / \mathrm{min}$ for increasing temperatures and $-10^{\circ} \mathrm{C} / \mathrm{min}$ for decreasing temperatures. All samples except APAF$6 \mathrm{FCl}$ had isothermal holds at $300^{\circ} \mathrm{C}$ for $1 \mathrm{~h}$.

Figure 1 presents TGA thermograms for samples considered in this study. Two distinct regions of mass loss are observed. Such results are common for TR polymers, where the first stage of mass loss is attributed to thermal rearrangement, and the second stage of mass loss is attributed to thermal degradation. ${ }^{2,5-8,16,21,24,54-61}$ By comparing these regions, the temperature range and intensity of thermal rearrangement and degradation 
can be identified. Derivative weight loss values, shown on the secondary ordinate, further assist these comparisons. Additionally, dashed lines are drawn on these plots to indicate the theoretical mass loss expected for complete, stoichiometric thermal rearrangement.

For TR polymers containing the same backbone structure, the ortho-functional leaving group strongly affects the thermal reactivity of these polymers. The first row in Figure 1 highlights these effects by comparing thermograms for three samples of HAB6FDA: HAB-6FDA-C (Figure 1A), which contains an acetyl leaving group, and HAB6FDA (Figure 1B) and HAB-6FDA-SS (Figure 1C), which contain hydroxyl leaving groups. The poly(hydroxyimide)s have similar thermograms, but the onset temperature and intensity of thermal rearrangement are much lower for HAB-6FDA-C. For HAB6FDA-C, thermal rearrangement can be detected below $300^{\circ} \mathrm{C}$, but the hydroxylfunctional samples do not lose mass until approximately $350^{\circ} \mathrm{C}$. Moreover, the derivative mass loss in the thermal rearrangement regime suggests faster reaction kinetics for the poly(hydroxyimide)s than the acetate-functional polyimide. The maximum in the derivative weight loss curve for the thermal rearrangement region is approximately 2.5 to 3 times stronger for the poly(hydroxyimide)s than for HAB-6FDA-C. Additionally, the temperature range for thermal rearrangement of the poly(hydroxyimide)s is narrower than that of HAB-6FDA-C, which indicates a more efficient reaction for the poly(hydroxyimide)s.

For the acetate-functional sample, the earlier onset and decreased intensity of thermal rearrangement relates to the TR reaction mechanism. Partially converted samples of HAB-6FDA-C contain some hydroxyl functionality, as determined from FTIR and NMR experiments. ${ }^{8,16}$ The acetate functionality first degrades to acetic acid, leaving 
a phenolic structure, which then undergoes thermal rearrangement. This two-step mechanism likely decreases the efficiency of the overall reaction; however, the stability of the acetyl group and lower $\mathrm{T}_{\mathrm{g}}$ of the polymer sample promotes an earlier onset temperature for thermal rearrangement. ${ }^{6}$

Modifying the polyimide diamine can also influence thermal rearrangement reactivity. The center column of Figure 1 (i.e., Figure 1B and Figure 1E) compares the thermograms between 6FDA-containing polyimides. The polymers differ in their diamine structures: Figure $1 \mathrm{~B}$ is the thermogram for HAB-6FDA, and Figure 1E is the thermogram for APAF-6FDA. The maximum derivative mass loss for HAB-6FDA is nearly three times that of APAF-6FDA, which indicates that HAB is more reactive than APAF. The hexafluoroisopropylidene groups that bridge the APAF diamine are strongly electron withdrawing, which is known to reduce the reactivity needed for forming high molecular weight polyimides. ${ }^{62}$ Our results suggest that similar principles apply for thermal rearrangement, whereby thermal rearrangement reactivity is lower for the APAF sample because of its hexafluoroisopropylidene functional group.

Steric effects may also influence thermal rearrangement reactivity. For APAFcontaining polyimides, changing the 6FDA dianhydride to a more flexible ODPA dianhydride increases the reactivity of the thermal rearrangement reaction, which has been attributed to the higher segmental mobility of ODPA-containing polyimides compared to more rigid, higher- $\mathrm{T}_{\mathrm{g}}$ polyimides. ${ }^{5,56}$ Figure $1 \mathrm{D}$ presents the thermogram for APAF-ODPA. For the thermal rearrangement region of this plot, the peak height for the derivative mass loss is almost twice that of the APAF-6FDA polyimide in Figure 1E. In addition to these steric effects, carbonyl electrophilicity may also influence thermal rearrangement. One would expect that ODPA, which has weaker electron-withdrawing 
characteristics than 6FDA, may decrease the electrophilicity of the imide carbonyl, ${ }^{63}$ thus decreasing the reactivity for thermal rearrangement. However, our ${ }^{13} \mathrm{C} \mathrm{NMR}$ results show similar chemical shifts between both imide carbonyls of approximately $166 \mathrm{ppm}$ (cf., Supporting Information). Therefore, steric effects play a more significant role in increasing the thermal rearrangement reactivity for ODPA-containing polyimides compared to 6FDA-containing polyimides.

A final comparison can be made between the thermal reactivity of the APAF6FDA polyimide (cf., Figure 1E) and the APAF-6FCl polyamide (cf., Figure 1F). While the degradation regimes for both of these polymers occurs predominately above $450^{\circ} \mathrm{C}$, the thermal rearrangement regime is quite different. The onset of thermal rearrangement for the polyimide begins at approximately $350^{\circ} \mathrm{C}$. However, the polyamide begins to undergo thermal rearrangement around $250^{\circ} \mathrm{C}$, indicating much higher thermal rearrangement reactivity for the $6 \mathrm{FCl}$ diacid chloride compared to the $6 \mathrm{FDA}$ dianhydride. This lower temperature window for thermal rearrangement further supports the work of Han et al. showing that TR polymers can be formed at much lower temperatures using polyamide-based precursors rather than polyimide-based precursors. $^{21}$ In this study, near-quantitative thermal rearrangement can be achieved at temperatures $100^{\circ} \mathrm{C}$ lower for a polyamide-based sample than for a polyimide of similar backbone structure. 


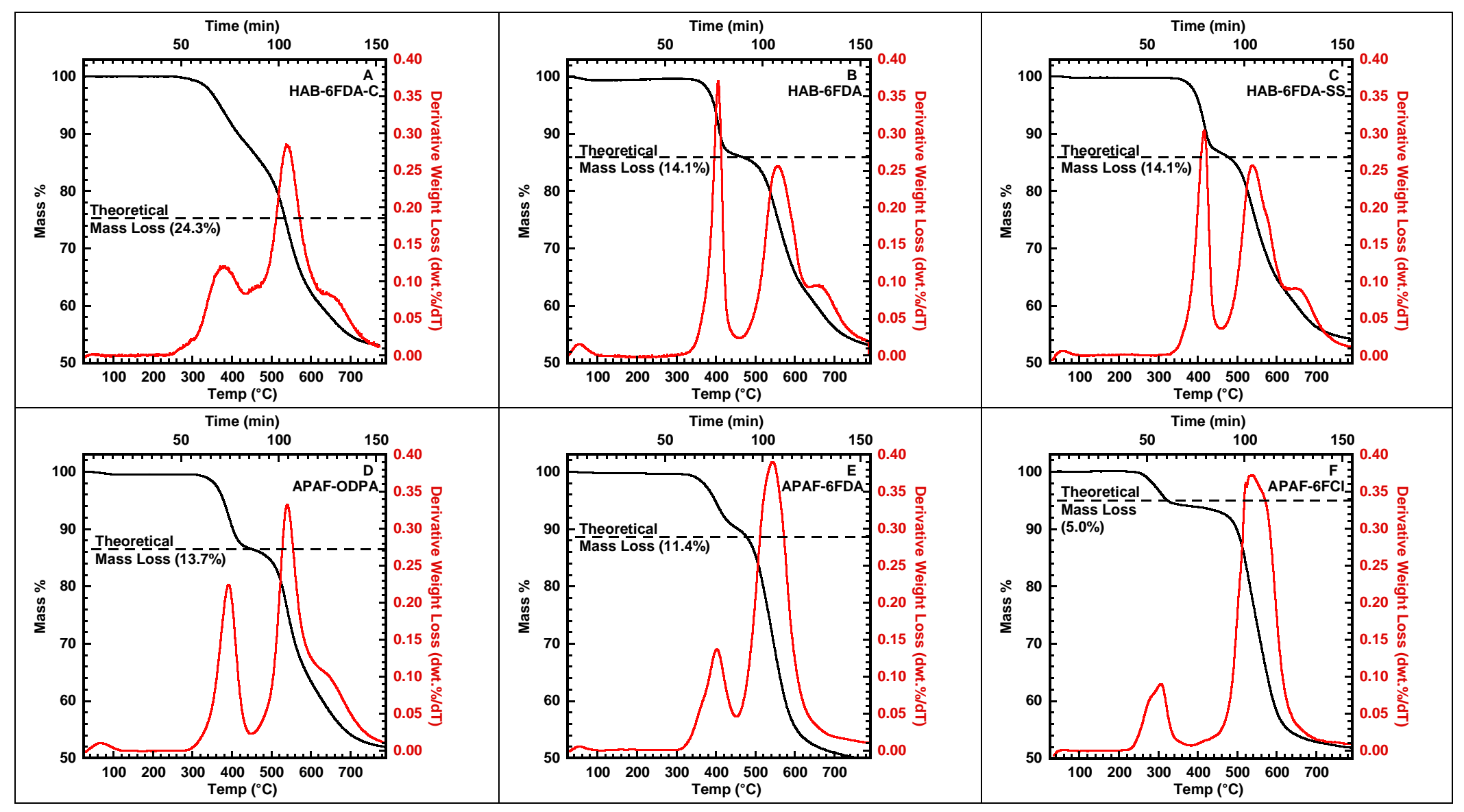

Figure 1. TGA thermograms of (A) HAB-6FDA-C, (B) HAB-6FDA, (C) HAB-6FDA-SS, (D) APAF-ODPA, (E) APAF6FDA, and (F) APAF-6FCl. Figures (E) and (F) reproduced from Smith et al. with permission. ${ }^{36}$ Theoretical mass loss was calculated as the mass loss expected for stoichiometric conversion of the polyimide or polyamide precursors to polybenzoxazoles (cf., Table 2). 


\section{Pure-gas permeabilities for the poly(hydroxyimide)s, poly(hydroxyamide), and corresponding TR polymers as a function of pressure}

The pure-gas permeabilities of $\mathrm{H}_{2}, \mathrm{CH}_{4}, \mathrm{~N}_{2}, \mathrm{O}_{2}$, and $\mathrm{CO}_{2}$ and five selected permselectivities for the precursor poly(hydroxyimide)s, poly(hydroxyamide), and corresponding TR polymers are presented in Table 3. More complete data, including plots of permeability as a function of pressure for all gases and polymers, are recorded in the Supporting Information. $\mathrm{H}_{2}, \mathrm{CH}_{4}$, and $\mathrm{CO}_{2}$ permeation properties for APAF-6FDA, APAF- $6 \mathrm{FCl}$ and their corresponding TR polymers are taken from our previous work. ${ }^{36}$

To more clearly show comparisons between transport properties for different gas pairs, upper bound plots for several gas pairs are shown in Figures 2 - 6. All TR polymer precursors are shown as open circles, and TR polymers are shown as open squares. Each precursor and analogous TR polymer are represented with the same colors, and discrete data points are shown for the permeability and selectivity of each pressure considered. The 2008 Robeson upper ${ }^{64}$ bound is shown on each figure, and, where available, transport properties for common, commercially relevant polymers, such as tetrabromo polycarbonate (TBPC), cellulose acetate (CA), polysulfone (PSF), Matrimid ${ }^{\circledR}$, and poly(2,6-dimethyl-1,4-phenylene oxide) (PPO) are included. ${ }^{1}$ 


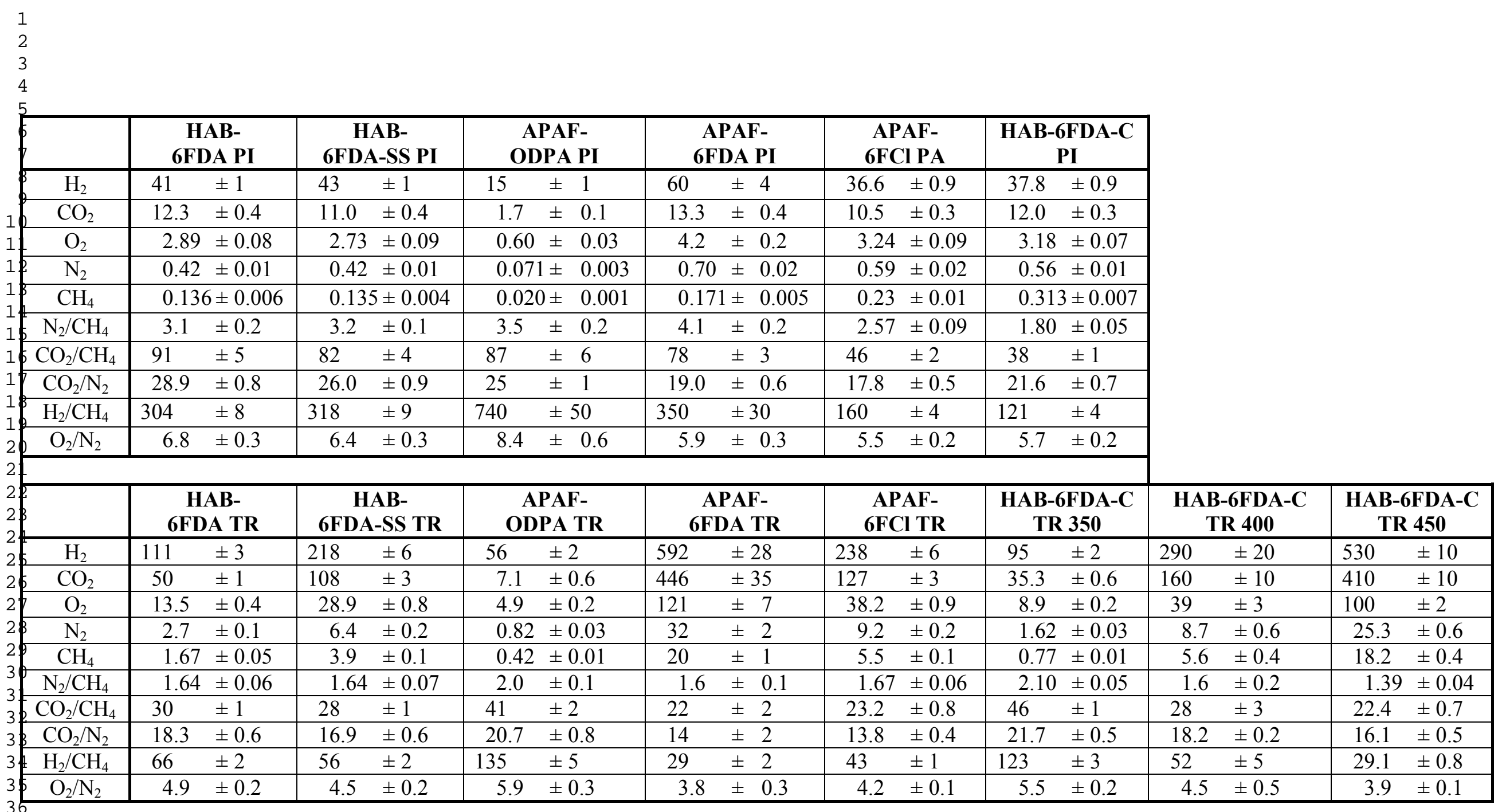

Table 3. Pure-gas permeabilities (in Barrer) of $\mathrm{H}_{2}, \mathrm{CO}_{2}, \mathrm{O}_{2}, \mathrm{~N}_{2}$, and $\mathrm{CH}_{4}$ for polyimides (PI), the poly(hydroxyamide) (PA), and their analogous TR polymers. Pure-gas selectivities for $\mathrm{N}_{2} / \mathrm{CH}_{4}, \mathrm{CO}_{2} / \mathrm{CH}_{4}, \mathrm{CO}_{2} / \mathrm{N}_{2}, \mathrm{H}_{2} / \mathrm{CH}_{4}$, and $\mathrm{O}_{2} / \mathrm{N}_{2}$ are also shown. Data are reported for $35^{\circ} \mathrm{C}$ and an upstream pressure of $10 \mathrm{~atm}$. Data for HAB-6FDA-C samples taken from ref ${ }^{15}$. 


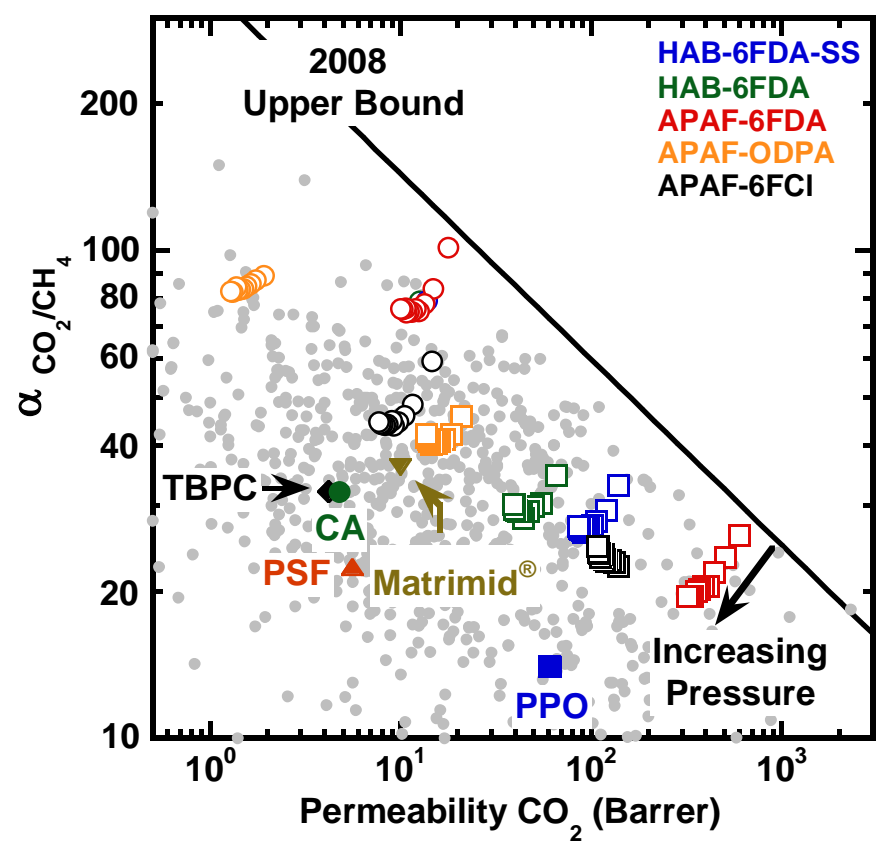

Figure 2. Upper bound comparison for the $\mathrm{CO}_{2} / \mathrm{CH}_{4}$ gas pair. Polyimide and polyamide precursors are shown as open circles, and TR polymers are shown as open squares. Literature data are shown as gray circles from Robeson's database, ${ }^{64}$ and additional industrially relevant polymers (tetrabromo polycarbonate (TBPC), cellulose acetate (CA), polysulfone (PSF), Matrimid ${ }^{\circledR}$, and poly(2,6-dimethyl-1,4-phenylene oxide) (PPO)) are highlighted from the review by Sanders et al. ${ }^{1}$ Data points are plotted for pure-gas permeability determined between approximately 1 and 50 bar with the exception of the HAB-6FDA and HAB-6FDA-SS polyimides, which are only plotted for pressures below their $\mathrm{CO}_{2}$ plasticization pressure point. Data for HAB-6FDA and HAB-6FDA-SS partially overlap data for APAF-6FDA. The change of permeability and selectivity with increasing pressure is indicated for the APAF-6FDA TR polymer. APAF-6FCl TR polymer shows increasing selectivity with increasing $\mathrm{CO}_{2}$ pressure, which likely indicates some $\mathrm{CO}_{2}$ plasticization. ${ }^{36}$ This figure was modified and reproduced from Smith et al. with permission. ${ }^{36}$ 


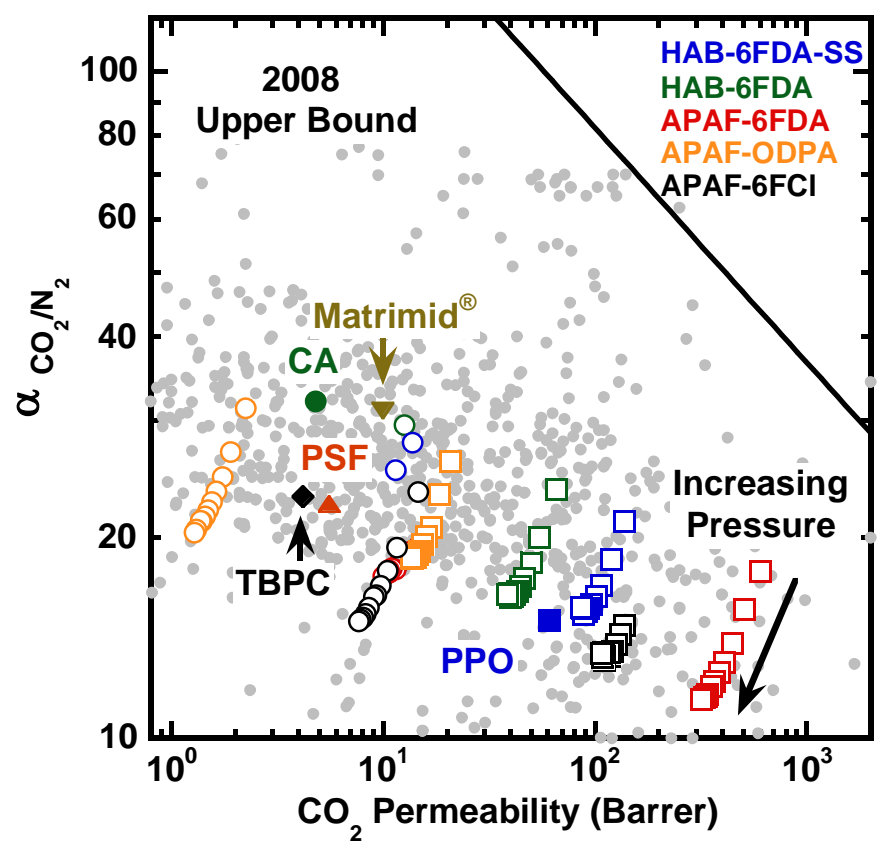

Figure 3. Upper bound comparison for the $\mathrm{CO}_{2} / \mathrm{N}_{2}$ gas pair. Polyimide and polyamide precursors are shown as open circles, and TR polymers are shown as open squares. Literature data are shown as gray circles from Robeson's database, ${ }^{64}$ and additional industrially relevant polymers (tetrabromo polycarbonate (TBPC), cellulose acetate (CA), polysulfone (PSF), Matrimid ${ }^{\circledR}$, and poly(2,6-dimethyl-1,4-phenylene oxide) (PPO)) are highlighted from the review by Sanders et al. ${ }^{1}$ Data points are plotted for pure-gas permeability determined between approximately 1 and 50 bar with the exception of the HAB-6FDA and HAB-6FDA-SS polyimides, which are only plotted for pressures below their $\mathrm{CO}_{2}$ plasticization pressure point. The change of permeability and selectivity with increasing pressure is indicated for the APAF-6FDA TR polymer. 


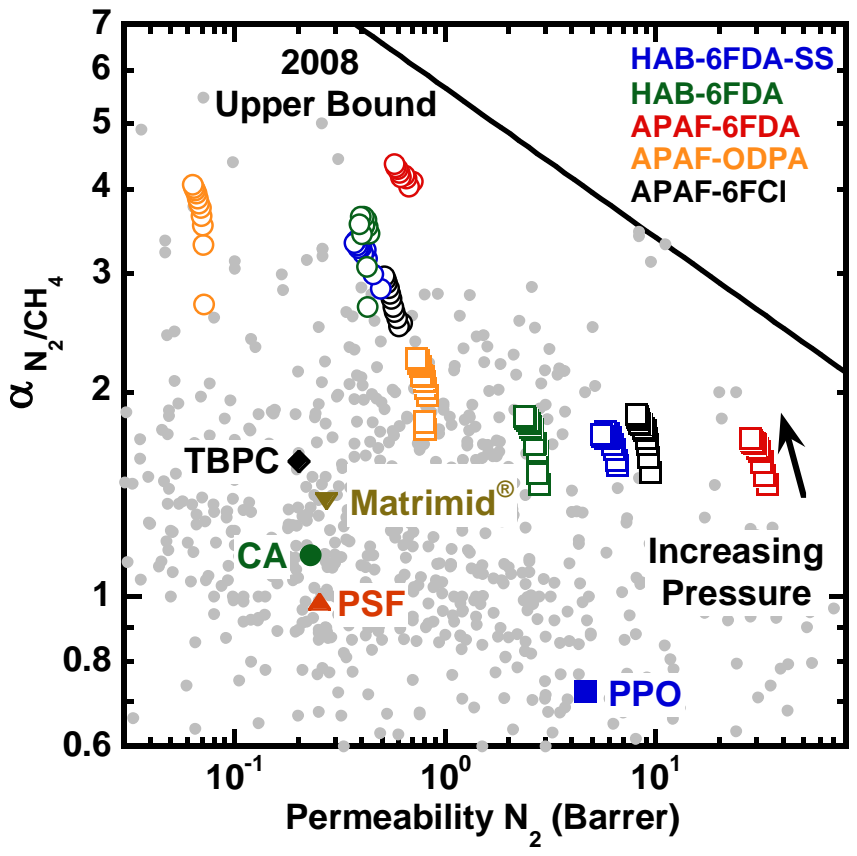

Figure 4. Upper bound comparison for the $\mathrm{N}_{2} / \mathrm{CH}_{4}$ gas pair. Polyimide and polyamide precursors are shown as open circles, and TR polymers are shown as open squares. Literature data are shown as gray circles from Robeson's database, ${ }^{64}$ and additional industrially relevant polymers (tetrabromo polycarbonate (TBPC), cellulose acetate (CA), polysulfone (PSF), Matrimid ${ }^{\circledR}$, and poly(2,6-dimethyl-1,4-phenylene oxide) (PPO)) are highlighted from the review by Sanders et al. ${ }^{1}$ Data points are plotted for pure-gas permeability determined between approximately 1 and 50 bar. The change of permeability and selectivity with increasing pressure is indicated for the APAF-6FDA TR polymer. 


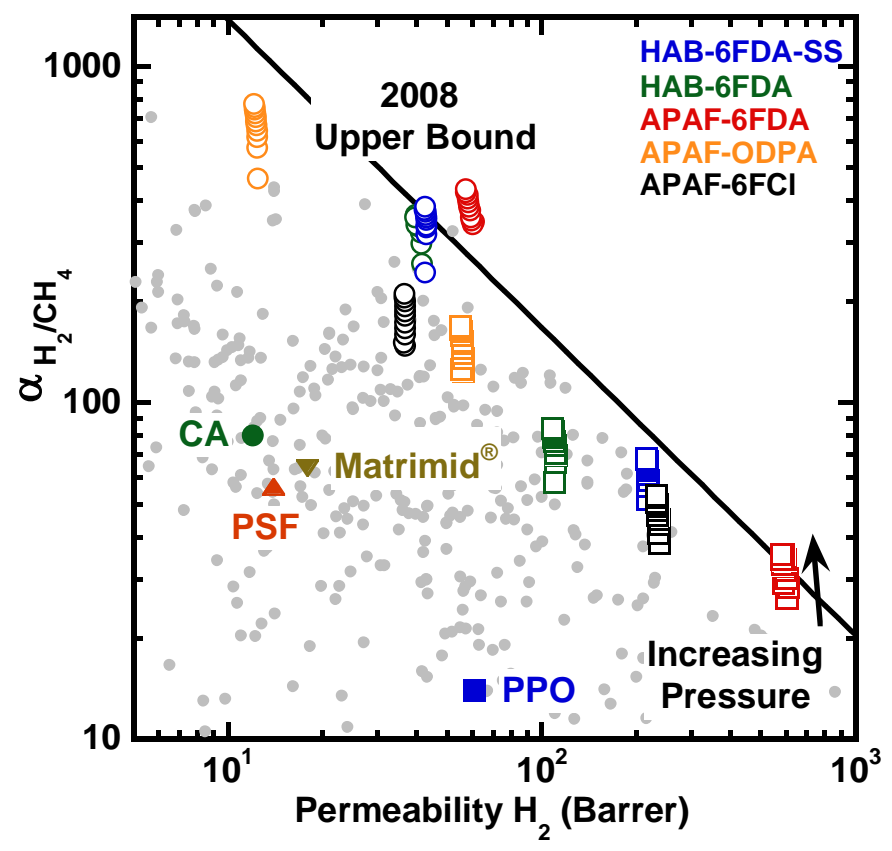

Figure 5. Upper bound comparison for the $\mathrm{H}_{2} / \mathrm{CH}_{4}$ gas pair. Polyimide and polyamide precursors are shown as open circles, and TR polymers are shown as open squares. Literature data are shown as gray circles from Robeson's database, ${ }^{64}$ and additional industrially relevant polymers (cellulose acetate (CA), polysulfone (PSF), Matrimid ${ }^{\circledR}$, and poly(2,6-dimethyl-1,4-phenylene oxide) (PPO)) are highlighted from the review by Sanders et al. ${ }^{1}$ Data points are plotted for pure-gas permeability determined between approximately 1 and 50 bar. The change of permeability and selectivity with increasing pressure is indicated for the APAF-6FDA TR polymer. This figure is modified and reproduced from Smith et al. with permission. ${ }^{36}$ 


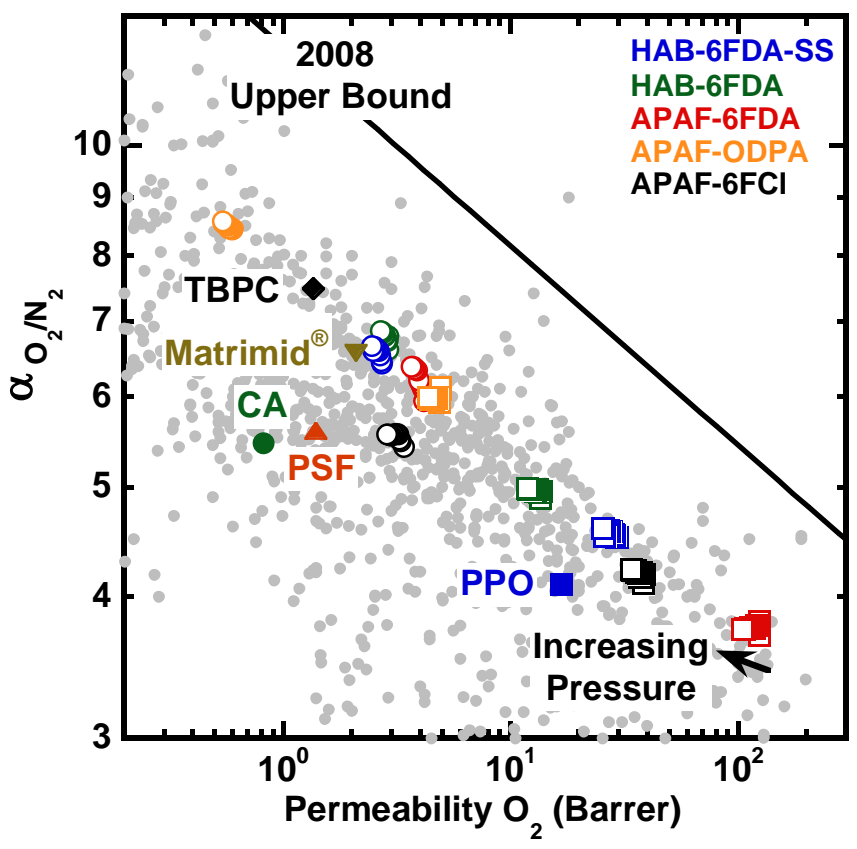

Figure 6. Upper bound comparison for the $\mathrm{O}_{2} / \mathrm{N}_{2}$ gas pair. Polyimide and polyamide precursors are shown as open circles, and TR polymers are shown as open squares. Literature data are shown as gray circles from Robeson's database, ${ }^{64}$ and additional industrially relevant polymers (tetrabromo polycarbonate (TBPC), cellulose acetate (CA), polysulfone (PSF), Matrimid ${ }^{\circledR}$, and poly(2,6-dimethyl-1,4-phenylene oxide) (PPO)) are highlighted from the review by Sanders et al. ${ }^{1}$ Data points are plotted for pure-gas permeability determined between approximately 1 and 50 bar. The change of permeability and selectivity with increasing pressure is indicated for the APAF-6FDA TR polymer.

\section{Effect of thermal rearrangement on transport properties}

Conversion of all poly(hydroxyimide) and poly(hydroxyamide) precursors to TR polymers resulted in increased gas permeability and a concomitant decreases in selectivity, which resulted in transport properties that roughly paralleled the upper bound. A vast body of work in the literature reports improvements in permeability-selectivity property sets for TR polymers compared to their precursors, ${ }^{2-4,7,8,15,57-59,65-67}$ and these improvements have been attributed to increases in free volume and a narrowing in free 
volume distribution or, in certain cases, the formation of a bimodal free volume distribution that occurs during the TR process. ${ }^{2,4,21,65,67-69}$

To investigate the role of thermal rearrangement on transport properties for our samples, we first discuss our results in comparison with other studies in the literature and then compare permeability and selectivity of our precursor and TR polymer samples using free volume theory.

Guo et al. and Sanders et al. investigated pure-gas permeabilities and selectivities for HAB-6FDA polyimides, including a solution-imidized polyimide, similar to the one investigated in this study, but prepared via an ester acid synthesis route and cast under slightly different conditions. ${ }^{8,10}$ Upon partial conversion of this sample at $350^{\circ} \mathrm{C}, \mathrm{CO}_{2}$ permeability increased by over a factor of 5 , and $\mathrm{CO}_{2} / \mathrm{CH}_{4}$ selectivity increased by $40 \%$, leading to an improvement in transport properties relative to the upper bound. Treatment temperatures of 400 and $450^{\circ} \mathrm{C}$ further increased permeability, but resulted in decreases in selectivity that moved these samples further from the upper bound. In fact, these authors reported very little improvement relative to the upper bound for their HAB-6FDA polyimide and most highly converted TR polymer, similar to the results we have determined in this study. ${ }^{8,10}$

The synthesis route used to prepare polyimide precursors can strongly affect TR polymer transport properties. Early studies on TR polymers focused exclusively on preparing samples from polyimides that were thermally imidized in the solid state, ${ }^{2,3,57,59}$ but it soon became apparent that TR polymer transport properties were affected by precursor synthesis route. The first paper describing these effects, by Han and colleagues, ${ }^{4}$ investigated the effect of polyimide synthesis route on transport properties for APAF-6FDA TR polymers, which were thermally rearranged at $450^{\circ} \mathrm{C}$ for $60 \mathrm{~min}$. 
Interestingly, in an upper bound comparison, they observed that TR polymers formed from solid-state imidized polyimides had property sets well beyond those formed from solution-imidized analogs; in fact, $\mathrm{CO}_{2}$ permeabilities were over an order of magnitude higher. ${ }^{4}$ Han et al. showed that these results were predominately related to the physical, not chemical structure of TR polymers: permeabilities correlated with differences in fractional free volume as determined by positron annihilation lifetime spectroscopy, among other characterization tests. ${ }^{4}$ For our study on HAB-6FDA, we also observed higher permeabilities for the TR polymer prepared from solid-state imidized polyimides. For $\mathrm{CO}_{2}$, permeabilities were approximately twice as high. These results suggest a similar mechanism of transport for our samples and the APAF-6FDA samples reported by Han et $a l .{ }^{4}$ However, unlike the APAF-6FDA samples, our TR polymers exhibited only minor shifts in their relation to the upper bound front: the solid-state imidized TR polymers (i.e., -SS) had higher permeabilities but similar or reduced selectivities relative to their solution imidized analogs. The molecular origins of these differences may relate to sample preparation (e.g., conversion times of either 30 or $60 \mathrm{~min}$ ) or to the difference in polymer backbone chemistry (e.g., HAB-6FDA versus APAF-6FDA).

Transport properties for the samples considered in this study tracked with free volume. In general, permeability increases and selectivity decreases with increasing free volume. Figures $7 \mathrm{~A}$ and $7 \mathrm{~B}$ present the relationship between free volume on permeability and selectivity for each sample. For the regions of these plots with overlapping data between precursors and TR polymers (i.e., the region between $\mathrm{V}_{\mathrm{f}}^{-1} \approx 5$ and $6 \mathrm{~nm}^{-3}$ ), TR polymer have higher permeabilities but lower selectivities than polyamides and polyimides with similar free volume. Such behavior suggests either broader free volume distributions for the TR polymers or some more complicated 
scenario, such as the formation of bimodal distributions. However, within our limited set of data, it is difficult, and perhaps overly speculative, to determine which of these interpretations, or combinations of these interpretations, are most suitable. Interestingly, the largest disparities in Figure 7 occur for the $\mathrm{H}_{2} / \mathrm{CH}_{4}, \mathrm{CO}_{2} / \mathrm{CH}_{4}$, and $\mathrm{N}_{2} / \mathrm{CH}_{4}$ gas pairs. For these gas pairs, the TR polymers consistently have permeabilities and selectivities that are further from the upper bound than polyimides with similar free volume.

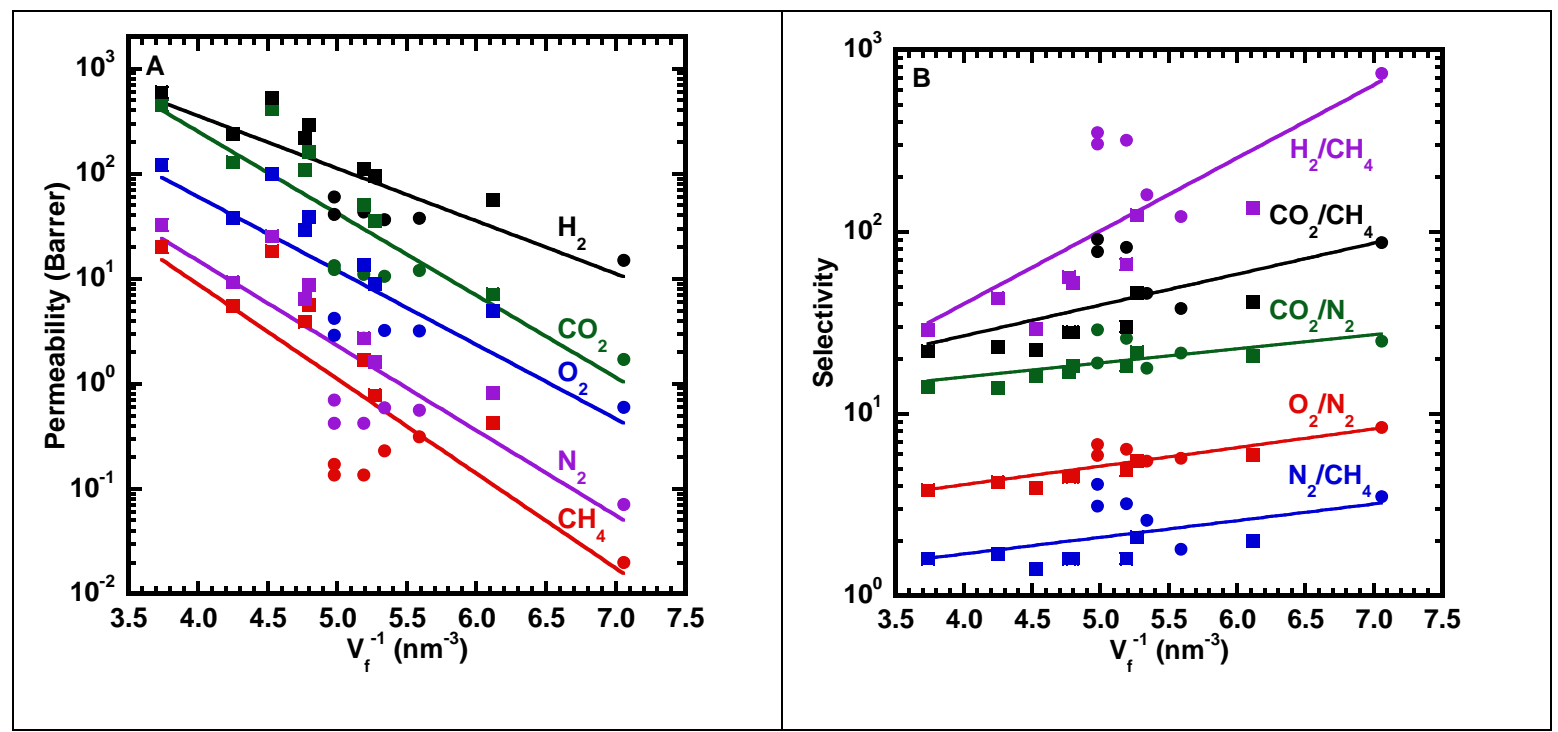

Figure 7. Comparison of (A) permeability and (B) selectivity as a function of average free volume element size determined by PALS. Precursors are shown as circles and TR polymers are shown as squares. Exponential fits to all data are shown to guide the eye.

\section{Effect of chemical structure on transport properties}

Figure 2 - 6 elucidate several structure-property relationships for polyimides and TR polymers. First, replacement of the hexafluoroisopropylidene-containing dianhydride with an ether-containing dianhydride has the strongest effect on gas permeability. Among the polyimide precursors, APAF-ODPA had permeabilities that were consistently 
lower than those of APAF-6FDA. For $\mathrm{N}_{2}$ and $\mathrm{CH}_{4}$, these permeabilities were nearly an order of magnitude lower. Similar trends in permeability have been reported for other ether versus hexafluoroisopropylidene-functional polyimides for propylene/propane separation. In a study by Shimazu et al., replacing a hexafluoroisopropylidene-functional group with an ether-functional group reduced propylene permeability by nearly an order of magnitude, and this decrease in permeability was almost exclusively associated with a decrease in gas diffusivity. ${ }^{70}$ The effect of ether versus hexafluoroisopropylidene structure is even more pronounced for the TR polymers. In the polyimides, for example, structural modification of ether to hexafluoroisopropylidene functionality increases $\mathrm{CO}_{2}$ permeability by a factor of 8 , but, for their corresponding TR polymers, this structural modification increases $\mathrm{CO}_{2}$ permeability by a factor of 62 . In terms of the solutiondiffusion model, increases in permeability between polyimides and TR polymers is most strongly correlated with increases in diffusivity. ${ }^{14,16}$ Therefore, replacing the rigid hexafluoroisopropylidene-functional 6FDA with a more flexible ether-functional ODPA results in more significant differences in permeability for TR polymers than their corresponding polyimide precursors.

Replacing the aromatic biphenyl diamine, HAB, with an aromatic hexafluoroisopropylidene-functional diamine, APAF, resulted in slight increases in permeability for the polyimides, but very large differences in permeabilities for the TR polymers. At 10 atm, the APAF-6FDA polyimide had $\mathrm{CO}_{2}$ and $\mathrm{N}_{2}$ permeabilities that were nearly $10 \%$ and $70 \%$ higher, respectively, than those of the HAB-6FDA polyimide. However, after conversion, $\mathrm{CO}_{2}$ and $\mathrm{N}_{2}$ permeabilities were nearly $900 \%$ and $1200 \%$ higher for the APAF-6FDA TR polymer compared to the HAB-6FDA TR polymer. 
These results, along with those for APAF-ODPA, highlight the importance in selecting highly permeable precursors when designing TR polymers with high permeability.

From the permeability results in Figure 5, all of the poly(hydroxyimide)s except APAF-ODPA reached or surpassed Robeson's $2008 \mathrm{H}_{2} / \mathrm{CH}_{4}$ upper bound. To investigate the morphology of these materials, Figure 8 presents $\mathrm{H}_{2}$ permeability and $\mathrm{H}_{2} / \mathrm{CH}_{4}$ selectivity as a function of free volume for all samples considered in this study. From these results, the tradeoff between free volume and permeability/selectivity is clear. However, compared to the other precursors and TR polymers, HAB-6FDA, HAB-6FDASS, and APAF-6FDA have unusually high selectivities relative to their given free volume, indicating that the hydroxyl group in these polyimides along with their rigid backbone structure, may provide a benefit to selectivity for the polyimides. On the other hand, APAF-ODPA, which also contains hydroxyl groups, may not have transport properties above the upper bound due to its flexible ether linkage.
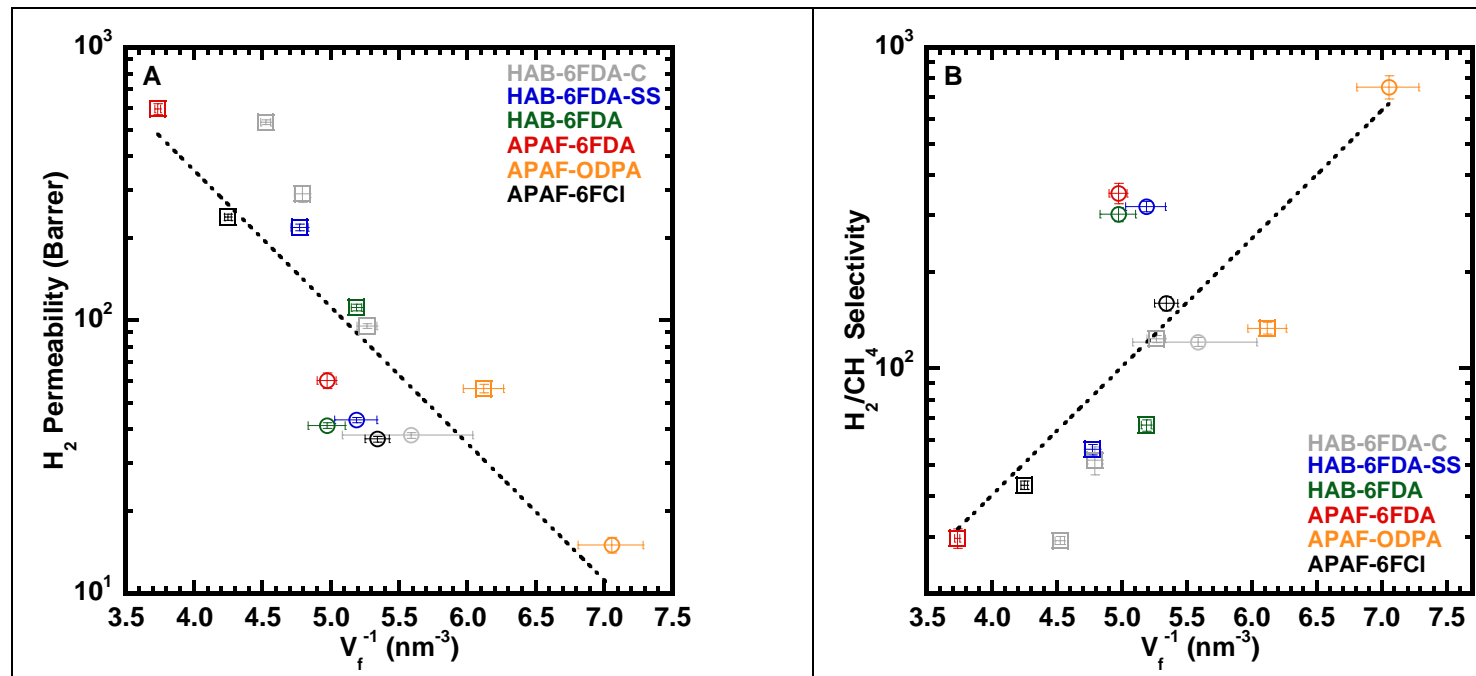

Figure 8. Comparison of (A) $\mathrm{H}_{2}$ permeability and (B) $\mathrm{H}_{2} / \mathrm{CH}_{4}$ selectivity as a function of average free volume element size determined by PALS. Precursors are shown as open circles, and TR polymers are shown as open squares. Error bars represent one standard deviation in uncertainty. Exponential fits to all data are provided to guide the eye. 


\section{Effect of polyamide versus polyimide precursor on transport properties}

The APAF-6FDA polyimide had transport properties that were closer to the upper bound than those of the APAF-6FCl polyamide. Similar results were reported by Park et $a l^{2}$ and Han et $a l^{21}$ for APAF-6FDA-SS and APAF-6FCl, respectively. Despite APAF6FDA and APAF-6FCl TR polymers having nearly identical structures, these polymers showed differences in transport properties for all gases considered. These differences are presumably related to the non-equilibrium nature of these materials, meta/para versus strictly para configuration for the two samples, and differences in crosslinking. ${ }^{36}$

\section{Study of conditioning and plasticization effects with hysteresis loops}

In the presence of high concentrations of condensable gases such as $\mathrm{CO}_{2}$, polymer membranes can undergo plasticization and conditioning. ${ }^{25,71-73}$ Plasticization is often observed when polymers undergo penetrant-induced swelling, which often increases gas diffusion. Conditioning of a polymer upon exposure to condensable gases also influences polymer swelling. However, this term is used to describe relatively long-lived changes in transport properties that result after removing a condensable penetrant. To separate the effects of plasticization and conditioning, permeability hysteresis curves were recorded to document the effect of $\mathrm{CO}_{2}$ exposure on transport properties.

The first set of samples considered are poly(hydroxyimide)s formed from thermal imidization in solution and their corresponding TR polymers. The hysteresis loops for HAB-6FDA and APAF-6FDA are shown in Figures 9 and 10, respectively. Similar to APAF-6FDA, APAF-ODPA showed no plasticization pressure point and little hysteresis (cf., Supporting Information). For the HAB-6FDA polyimide, a plasticization pressure is 
observed for the first pressurization step between approximately 10 and $15 \mathrm{~atm}$, which is a similar location for the plasticization pressure of HAB-6FDA-C. ${ }^{32}$ Such plasticization pressures are also common for other polyimides, such as untreated Matrimid ${ }^{\circledR}$ (DAPIBTDA) ${ }^{74}$ MDA-6FDA polyimide, ${ }^{75}$ 6FpDA-6FDA,${ }^{28}$ and uncrosslinked DAM:DABA6FDA. ${ }^{76}$ However, after thermal rearrangement, Figure 9B indicates no plasticization pressure for the HAB-6FDA TR polymer. Similar suppression of plasticization due to thermal rearrangement has been documented by Gleason et al. ${ }^{32}$ In addition to plasticization, hysteresis results show a strong conditioning effect for the polyimide, but more limited conditioning in the TR polymer. At $10 \mathrm{~atm}, \mathrm{CO}_{2}$ permeability is over $200 \%$ higher for HAB-6FDA polyimide upon depressurization. However, $\mathrm{CO}_{2}$ permeability is only $20 \%$ higher for the HAB-6FDA TR polymer. Upon re-pressurization, the polyimide has higher permeability, but the TR polymer has almost completely recovered. Within the uncertainty of the measurements, the first and second pressurization steps overlap for the TR polymer for almost every pressurization point. In contrast, permeability is consistently higher for the second pressurization step compared to the first for the precursor polyimide. 
Figure 9. $\mathrm{CO}_{2}$ hysteresis loops for HAB-6FDA (A) polyimide and (B) TR polymer.

No plasticization pressure and little conditioning at feed pressures up to 50 bar are observed for TR polymers prepared from poly(hydroxyimide)s. Interestingly, the APAF6FDA and APAF-ODPA polyimides (cf., Figure 10 and the Supporting Information, respectively) showed no plasticization pressure point and little hysteresis. For the APAFODPA polyimide, the difference in plasticization pressure response may relate to crosslinking occurring during solvent removal. The HAB-6FDA polymer had a $0 \%$ gel fraction after a three day exposure test in DMAc with a Soxhlet extractor, but the APAFODPA sample had a gel fraction of $49.8 \%$. Solvent was removed from all of the poly(hydroxyimide)s at $270^{\circ} \mathrm{C}$, which is slightly above the $\mathrm{T}_{\mathrm{g}}$ of APAF-ODPA $\left(266^{\circ} \mathrm{C}\right)$ but below the $\mathrm{T}_{\mathrm{g}}$ of the other poly(hydroxyimide)s. The solvent removal temperature being above the $\mathrm{T}_{\mathrm{g}}$ may allow sufficient chain flexibility in APAF-ODPA to induce crosslinking. Interestingly, the APAF-6FDA polyimide, which did not show a 
plasticization pressure, also had a 0\% gel fraction like HAB-6FDA. A macromolecular explanation for the relative stability of APAF-6FDA is currently unknown.

Nearly identical hysteresis curves were observed for the solution and solid-state thermally imidized HAB-6FDA samples. The HAB-6FDA-SS polyimide also had a $0 \%$ gel fraction, dissolving after a three day exposure test to DMAc, so it is presumably not crosslinked. The hysteresis curve for HAB-6FDA-SS is included in the Supporting Information.

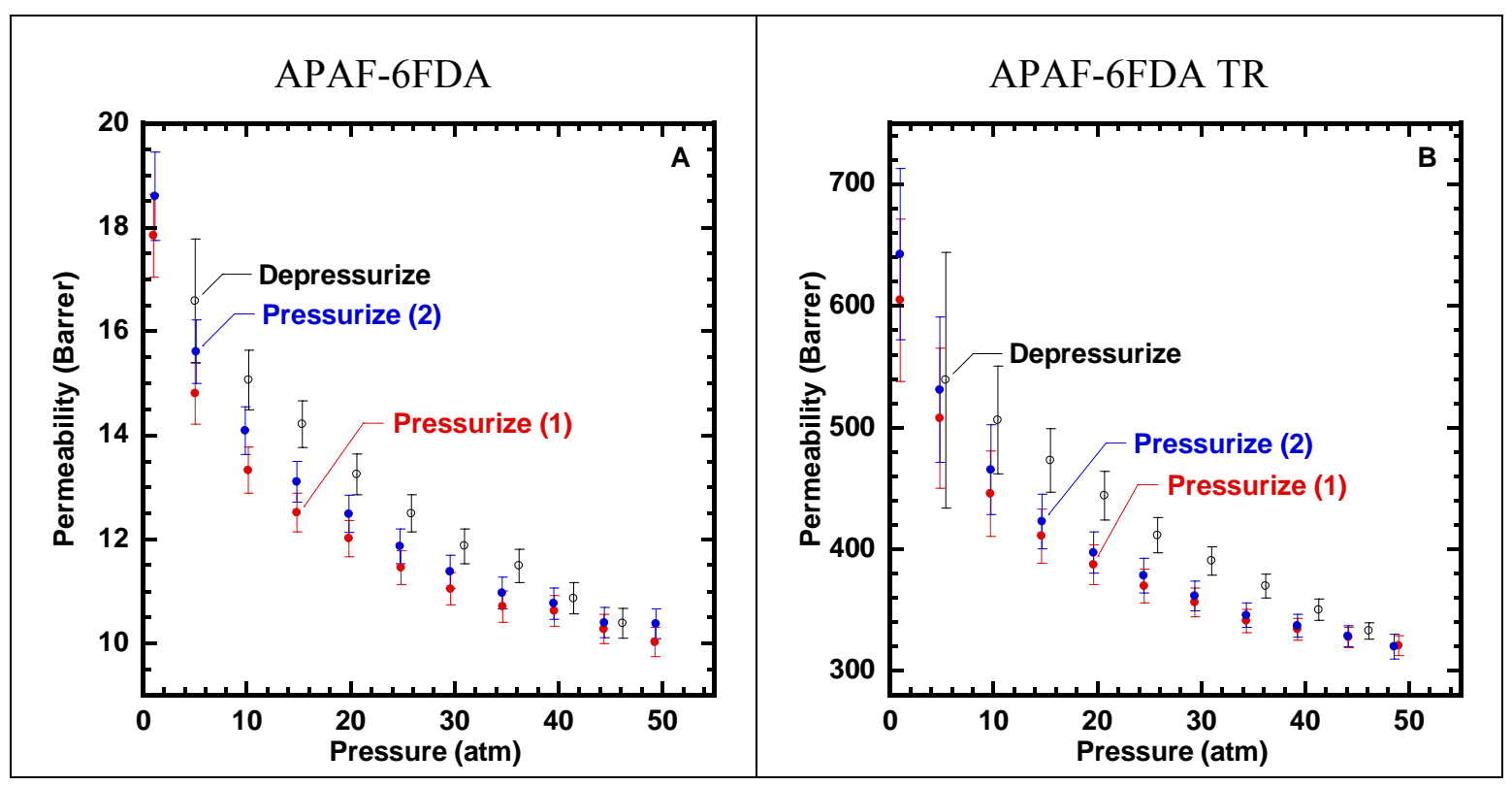

Figure 10. $\mathrm{CO}_{2}$ hysteresis loops for APAF-6FDA (A) polyimide and (B) TR polymer.

Similar to the APAF-6FDA polyimide, the APAF-6FCl polyamide hysteresis loop in Figure 11A shows no indication of plasticization pressure. The APAF-6FCl TR hysteresis loop in Figure 11B did not show a plasticization pressure either, but there was a stronger hysteresis effect for this sample compared to that of its polyamide precursor. Moreover, at lower pressures, differences in permeabilities are observed between the first 
and second pressurization steps suggesting some plasticization. The APAF-6FCl TR polymer appears to show slight increases in $\mathrm{CO}_{2} / \mathrm{CH}_{4}$ selectivity with increasing pressure (cf., Figure 2), so although no plasticization pressure is observed, this sample may undergoing slow structural relaxation during these experiments.

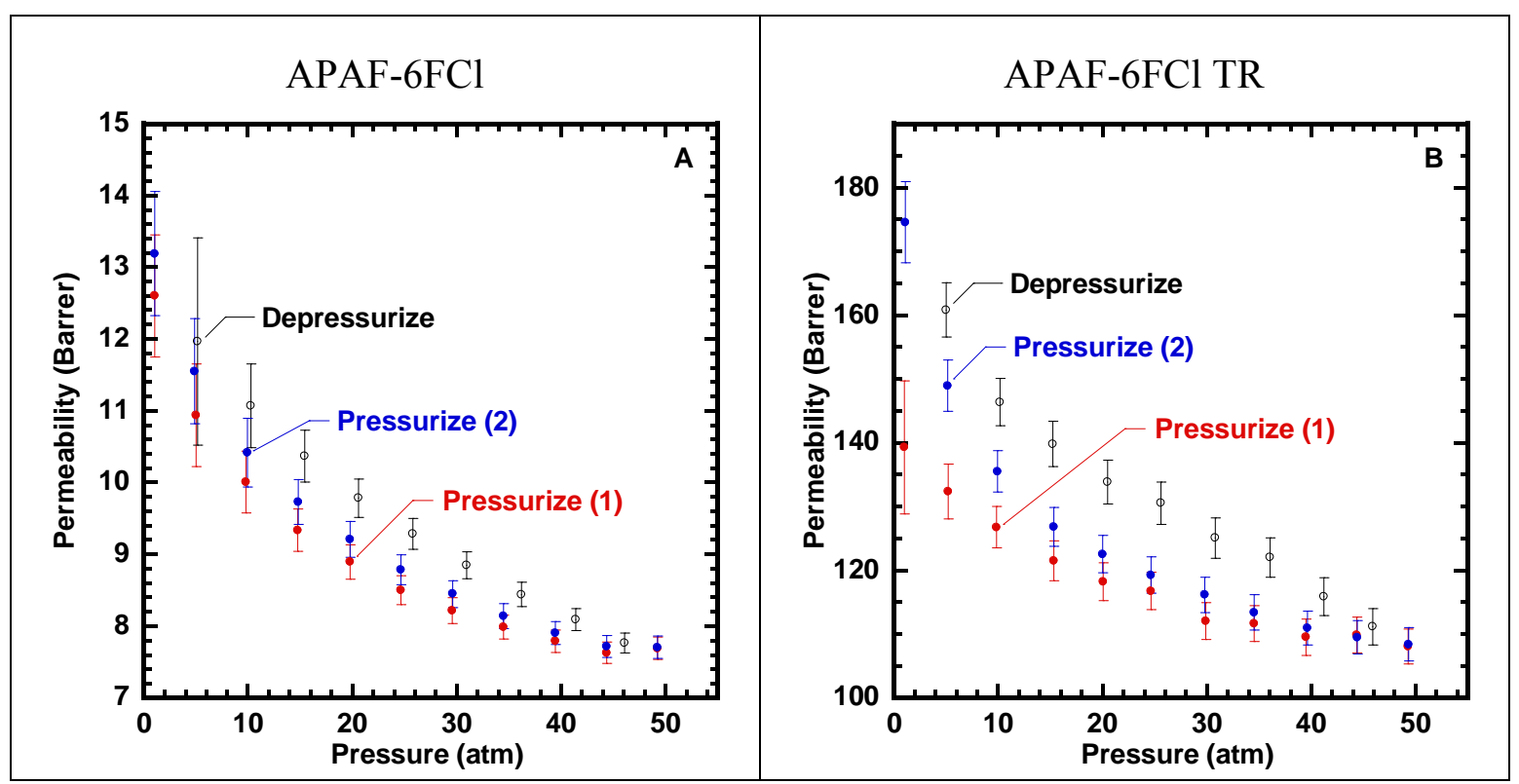

Figure 11. $\mathrm{CO}_{2}$ hysteresis loops for $\mathrm{APAF}-6 \mathrm{FCl}(\mathrm{A})$ polyamide and (B) TR polymer.

\section{Olefin-paraffin permeation properties of APAF-6FDA TR polymer}

Ethylene and ethane permeation results are presented in Figure 12A the propylene and propane results are presented in Figure 12B for the APAF-6FDA TR polymer. Dualmode behavior is observed at low activities, which is indicated by decreasing permeability with increasing pressure. ${ }^{77}$ Furthermore, paraffin permeability is lower than olefin permeability, and olefin/paraffin permeabilities increase in the following order: $\mathrm{C}_{3} \mathrm{H}_{8}<\mathrm{C}_{2} \mathrm{H}_{6}<\mathrm{CH}_{4} \approx \mathrm{C}_{3} \mathrm{H}_{6}<\mathrm{C}_{2} \mathrm{H}_{4}$. At the experimental temperature considered (i.e., 
$35^{\circ} \mathrm{C}$ ), ethylene and ethane are both supercritical gases, which necessitated an extrapolation of their saturation fugacities to the temperature of interest to determine their gas phase activities. ${ }^{78}$ Propylene and propane, however, are below their critical temperature, so their saturation fugacities were determined from the Wagner equation. ${ }^{78}$

For our olefin and paraffin experiments, non-idealities in pressure-based permeabilities need to be corrected. Otherwise, misleading conclusions regarding plasticization could be gleaned from these results. From Equation 1 in the experimental section, permeability is calculated from a pressure- and thickness-normalized flux across a film. For gases that exhibit strong non-idealities, such as olefins and paraffins, the pressure-normalized flux needs to be replaced with a fugacity-normalized flux. Figure 13 presents normalized permeabilities for $\mathrm{C}_{2} \mathrm{H}_{4}, \mathrm{C}_{2} \mathrm{H}_{6}, \mathrm{C}_{3} \mathrm{H}_{6}, \mathrm{C}_{3} \mathrm{H}_{8}$, and $\mathrm{CO}_{2}$ as a function of activity. Figure 13A presents permeabilities calculated based on pressure, and Figure 13B presents permeabilities calculated based on fugacity. Clearly, the most disparate interpretation between these plots occurs for $\mathrm{C}_{2} \mathrm{H}_{4}$ and $\mathrm{C}_{2} \mathrm{H}_{6}$. When considering pressure-based permeabilities (cf., Figure 13A), these results indicate that no plasticization pressure point is reached for either gas. However, when considering fugacity-based permeabilities, a clear plasticization pressure point is observed at activities near 0.30 . While the trend for changes in permeability for $\mathrm{C}_{3} \mathrm{H}_{6}$ and $\mathrm{C}_{3} \mathrm{H}_{8}$ is similar between pressure and fugacity-based permeability, we present these data (cf., Figure 12B) on a fugacity basis for consistency with our olefin/paraffin study. At the activities considered for $\mathrm{CO}_{2}$, there are differences in $\mathrm{CO}_{2}$ permeability when calculated with pressure or fugacity. However, the trends in $\mathrm{CO}_{2}$ permeation remain the same regardless of the calculation method used. Therefore, we have reported $\mathrm{CO}_{2}$ 
permeabilities based on pressure, but we have calculated $\mathrm{C}_{2} \mathrm{H}_{4}, \mathrm{C}_{2} \mathrm{H}_{6}, \mathrm{C}_{3} \mathrm{H}_{6}$, and $\mathrm{C}_{3} \mathrm{H}_{8}$ permeabilities based on fugacity.

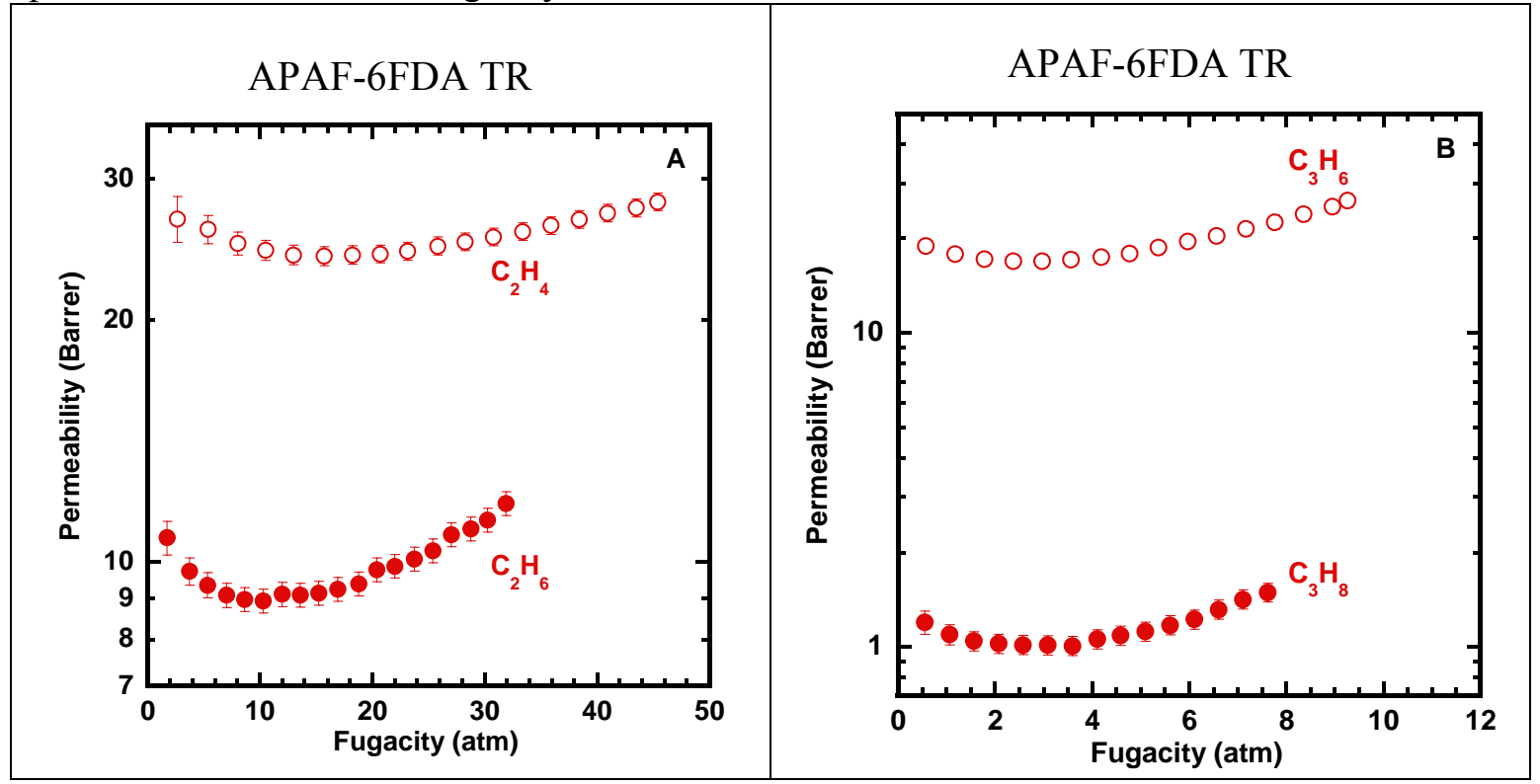

Figure 12. Permeability of ethylene, ethane, propylene, and propane as a function of feed fugacity in APAF-6FDA TR at $35^{\circ} \mathrm{C}$. Olefins are shown as open circles, and paraffins are shown as filled circles. Uncertainties were estimated as one standard deviation based on the propagation of error technique described by Bevington and Robinson. $^{79}$
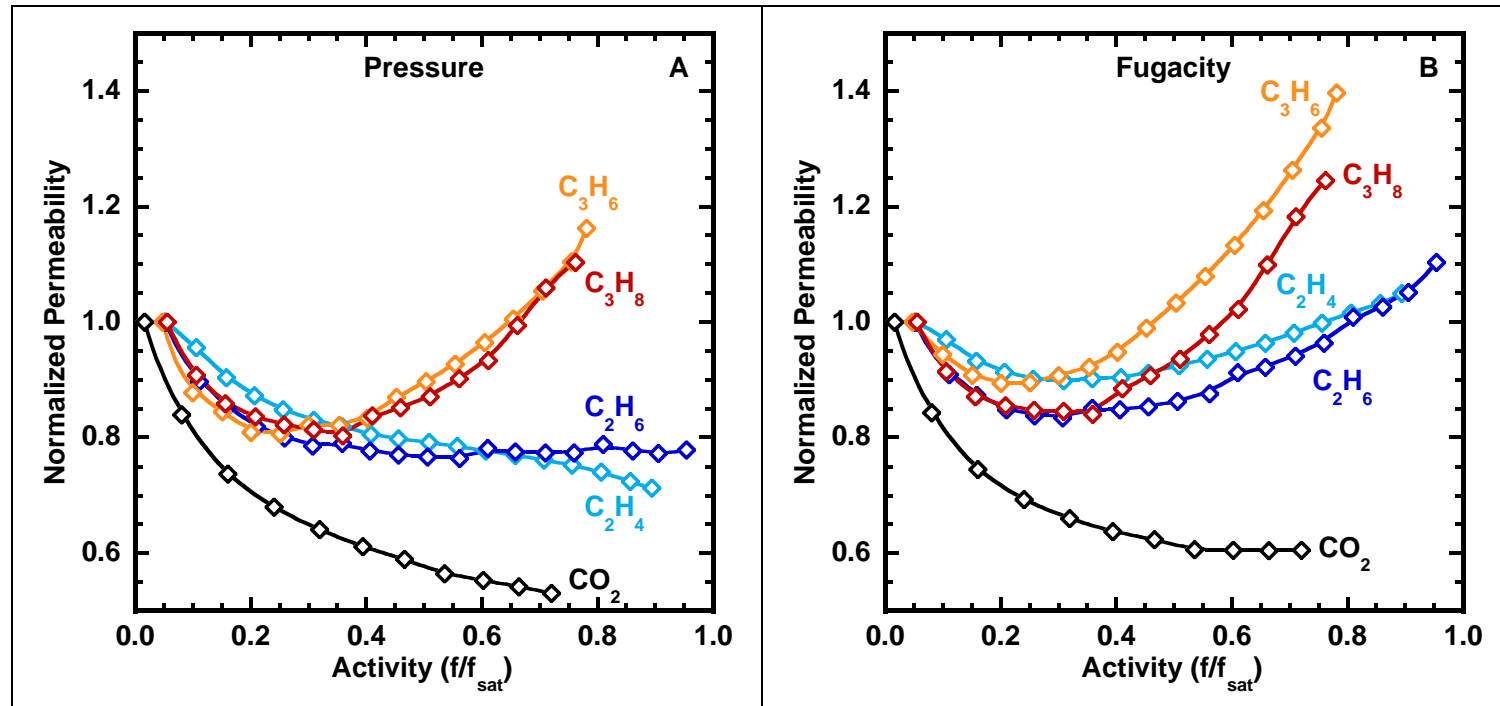
Figure 13. Comparison of normalized permeabilities as a function of activity when permeability is calculated based on (A) upstream pressure or (B) upstream fugacity for APAF-6FDA TR.

Upper bound data is presented for ethylene/ethane in Figure 14 and for propylene/propane in Figure 15. Pure-gas selectivities were calculated by fitting a smooth fit to the data in Figure 12 and determining the ratio of permeabilities over the range of pressure considered. Therefore, the ethylene/ethane data points represent permeabilities and selectivities up to approximately 46 atm, and the propylene/propane data points represent permeabilities and selectivities up to approximately $8.5 \mathrm{~atm}$. For ethylene/ethane separation, the selectivity of the APAF-6FDA TR polymer is $<3$, and this data lies below the upper bound. However, for propylene/propane, the APAF-6FDA TR polymer falls above the current upper bound.

The polymer upper bound for ethylene/ethane and propylene/propane are defined by a limited number of polymers, and the polymers closest to the upper bound are 6FDAcontaining polyimides. $^{33,80}$ For the ethylene/ethane gas pair, 6FDA-NDA polyimide defines the upper bound, ${ }^{80}$ and for the propylene/propane gas pair, 6FDA-DDBT and 6FDA-TrMPD polymers define the upper bound. ${ }^{33}$ Therefore, certain chemical structures that have upper bound separation performance for the ethylene/ethane gas pair may not have upper bound separation performance for the propylene/propane gas pair, and vice versa, which appears to be the case here for APAF-6FDA TR polymer. Nevertheless, these results indicate that TR polymers formed from near-upper bound precursor polyimides may be of interest for olefin/paraffin separation. 


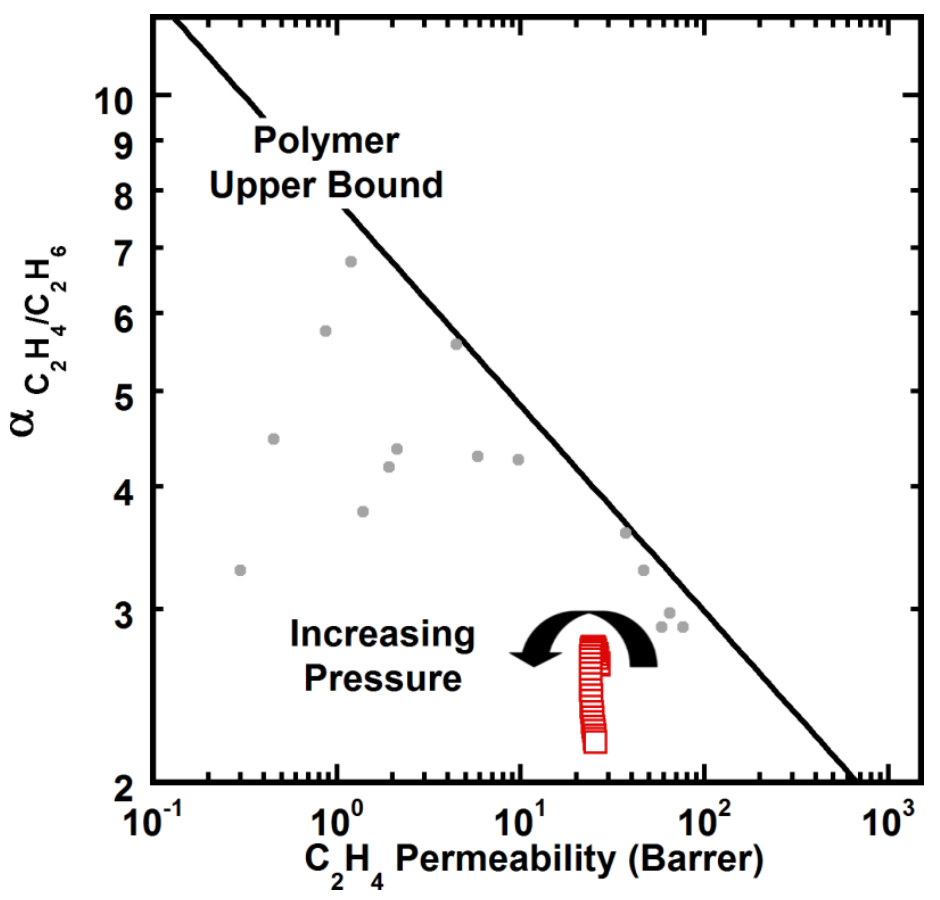

Figure 14. Upper bound comparison for $\mathrm{C}_{2} \mathrm{H}_{4} / \mathrm{C}_{2} \mathrm{H}_{6}{ }^{80}$ The APAF-6FDA TR polymer data is presented up to pressures of approximately $46 \mathrm{~atm}$. 


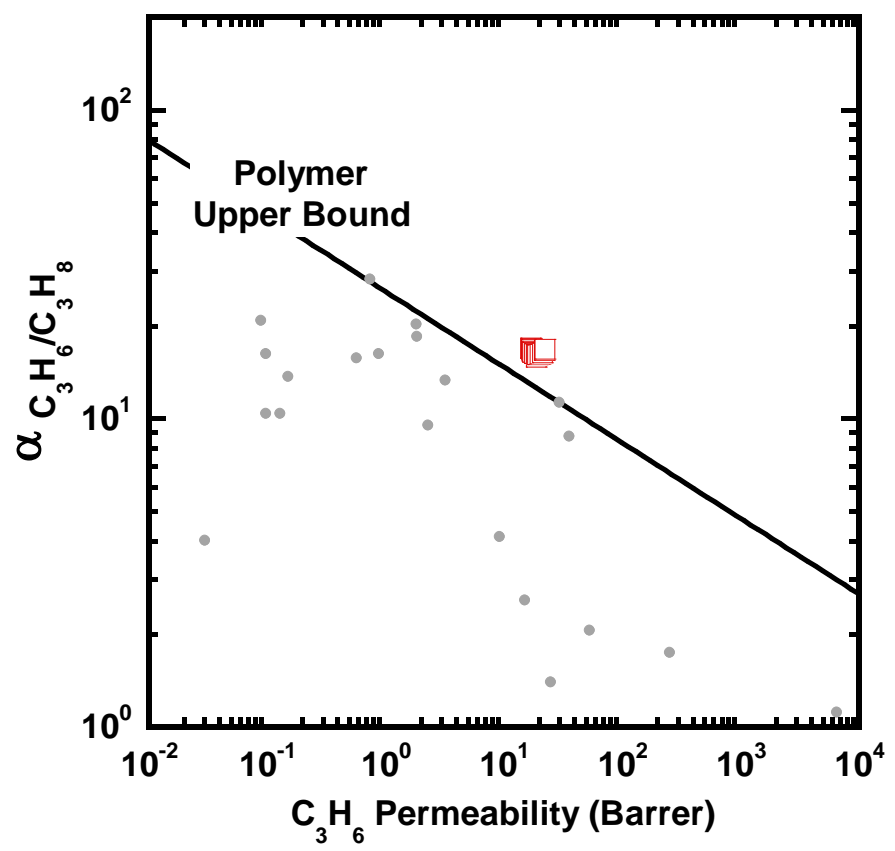

Figure 15. Upper bound comparison for $\mathrm{C}_{3} \mathrm{H}_{6} / \mathrm{C}_{3} \mathrm{H}_{8}{ }^{33}$ The APAF-6FDA TR polymer data is presented up to pressures of approximately $8.5 \mathrm{~atm}$.

\section{CONCLUSiOnS}

Several polyimides and a polyamide containing reactive functional groups suitable for forming thermally rearranged polymers were synthesized. These polymers include three polyimides (i.e., HAB-6FDA, APAF-6FDA, APAF-ODPA) and a polyamide (i.e., APAF-6FCl). Thermogravimetric analysis shows that the HABcontaining polymers are more reactive than those containing APAF moieties. Furthermore, the flexible ether linkage in ODPA increases the reactivity of the thermal rearrangement reaction relative to 6FDA-containing polyimides. Higher combinations of gas permeability and selectivity are observed for polyimides compared to polyamides and for polyimides containing hexafluoroisopropylidene linkages. Additionally, TR polymers 
formed from better performing precursors are typically closer to the upper bound, indicating that transport properties for TR polymer precursors can be used to gauge the relative performance of TR polymers. One exception to this correlation is for TR polymer precursors formed from different synthesis routes. For HAB-6FDA, TR polymers synthesized from a solid-state imidized polyimide were slightly closer to the upper bound than the sample synthesized via thermal imidization in solution. Differences in transport properties between these samples likely relates to differences in their casting and imidization procedure (i.e., thermal processing history). Plasticization and conditioning of all samples were analyzed by $\mathrm{CO}_{2}$ permeability hysteresis curves. $\mathrm{HAB}$ 6FDA samples (thermally imidized in solution and in the solid-state) were the only samples to show evidence of plasticization in permeability pressures curves. Conversion of HAB-6FDA to its corresponding TR polymer resulted in increased permeability and no plasticization pressure. None of the other samples showed $\mathrm{CO}_{2}$ plasticization pressures up to 50 bar, which may indicate plasticization resistance for several TR polymer precursors. The TR polymer formed from APAF-6FDA was tested for $\mathrm{C}_{2} \mathrm{H}_{4}$, $\mathrm{C}_{2} \mathrm{H}_{6}, \mathrm{C}_{3} \mathrm{H}_{6}$, and $\mathrm{C}_{3} \mathrm{H}_{8}$ permeability, and this sample showed separation performance beyond the polymer upper bound for propylene/propane separation. These transport results may indicate that the APAF-6FDA TR polymer may have a favorable diffusion selectivity for $\mathrm{C}_{3} \mathrm{H}_{6} / \mathrm{C}_{3} \mathrm{H}_{8}$, similar to other highly selective glassy polymers for this separation.

\section{ACKNOWLEDGEMENTS}

The authors gratefully acknowledge support from Grant DE-FG02-02ER15362, which was administered by the U.S. Department of Energy (DOE) Division of Chemical 
Sciences, Geosciences, and Biosciences through the Office of Basic Energy Sciences. Additionally, the authors gratefully acknowledge support from the DOE Office of Science Graduate Fellowship Program, which is managed under DOE contract number DE-AC05-06OR23100 by Oak Ridge Associated Universities (ORAU) and administered by the Oak Ridge Institute for Science and Education (ORISE).

\section{REFERENCES}

1. Sanders, D.F., Z.P. Smith, R. Guo, L.M. Robeson, J.E. McGrath, D.R. Paul, and B.D. Freeman, Energy-efficient polymeric gas separation membranes for a sustainable future: A review. Polymer, 2013. 54(18), 4729-4761.

2. Park, H.B., C.H. Jung, Y.M. Lee, A.J. Hill, S.J. Pas, S.T. Mudie, E. Van Wagner, B.D. Freeman, and D.J. Cookson, Polymers with cavities tuned for fast selective transport of small molecules and ions. Science, 2007. 318(5848), 254-258.

3. Park, H.B., S.H. Han, C.H. Jung, Y.M. Lee, and A.J. Hill, Thermally rearranged (TR) polymer membranes for $\mathrm{CO}_{2}$ separation. Journal of Membrane Science, 2010. 359(1-2), 11-24.

4. Han, S.H., N. Misdan, S. Kim, C.M. Doherty, A.J. Hill, and Y.M. Lee, Thermally rearranged (TR) polybenzoxazole: Effects of diverse imidization routes on physical properties and gas transport behaviors. Macromolecules, 2010. 43(18), 7657-7667.

5. Calle, M., Y. Chan, H.J. Jo, and Y.M. Lee, The relationship between the chemical structure and thermal conversion temperatures of thermally rearranged (TR) polymers. Polymer, 2012. 53(13), 2783-2791.

6. Guo, R., D.F. Sanders, Z.P. Smith, B.D. Freeman, D.R. Paul, and J.E. McGrath, Synthesis and characterization of thermally rearranged (TR) polymers: Effect of glass transition temperature of aromatic poly(hydroxyimide) precursors on TR process and gas permeation properties. Journal of Materials Chemistry A, 2013. 1(19), 6063-6072. 
7. Calle, M. and Y.M. Lee, Thermally rearranged (TR) poly(ether-benzoxazole) membranes for gas separation. Macromolecules, 2011. 44(5), 1156-1165.

8. Guo, R., D.F. Sanders, Z.P. Smith, B.D. Freeman, D.R. Paul, and J.E. McGrath, Synthesis and characterization of thermally rearranged (TR) polymers: Influence of ortho-positioned functional groups of polyimide precursors on TR process and gas transport properties. Journal of Materials Chemistry A, 2013. 1(2), 262-272.

9. Sanders, D.F., R. Guo, Z.P. Smith, Q. Liu, K.A. Stevens, J.E. McGrath, D.R. Paul, and B.D. Freeman, Influence of polyimide precursor synthesis route and ortho-position functional group on thermally rearranged (TR) polymer properties: Conversion and free volume. Polymer, 2014. 55(7), 1636-1647.

10. Sanders, D.F., R. Guo, Z.P. Smith, K.A. Stevens, Q. Liu, J.E. McGrath, D.R. Paul, and B.D. Freeman, Influence of polyimide precursor synthesis route and ortho-position functional group on thermally rearranged (TR) polymer properties: Pure gas permeability and selectivity. Journal of Membrane Science, 2014. $463,73-81$.

11. Tanaka, K., H. Kita, M. Okano, and K.-i. Okamoto, Permeability and permselectivity of gases in fluorinated and non-fluorinated polyimides. Polymer, 1992. 33(3), 585-592.

12. Kim, T.H., W.J. Koros, G.R. Husk, and K.C. Obrien, Relationship between gas separation properties and chemical-structure in a series of aromatic polyimides. Journal of Membrane Science, 1988. 37(1), 45-62.

13. Stern, S.A., Y. Mi, H. Yamamoto, and A.K.S. Clair, Structure/permeability relationships of polyimide membranes. Applications to the separation of gas mixtures. Journal of Polymer Science Part B: Polymer Physics, 1989. 27(9), 18871909.

14. Kim, S., H.J. Jo, and Y.M. Lee, Sorption and transport of small gas molecules in thermally rearranged (TR) polybenzoxazole membranes based on 2,2-bis(3amino-4-hydroxyphenyl)-hexafluoropropane (bisAPAF) and 4,4'hexafluoroisopropylidene diphthalic anhydride (6FDA). Journal of Membrane Science, 2013. 441, 1-8.

15. Sanders, D.F., Z.P. Smith, C.P. Ribeiro, R.L. Guo, J.E. McGrath, D.R. Paul, and B.D. Freeman, Gas permeability, diffusivity, and free volume of thermally rearranged polymers based on 3,3'-dihydroxy-4,4'-diamino-biphenyl (HAB) and 
2,2'-bis-(3,4-dicarboxyphenyl) hexafluoropropane dianhydride (6FDA). Journal of Membrane Science, 2012. 409, 232-241.

16. Smith, Z.P., D.F. Sanders, C.P. Ribeiro Jr, R. Guo, B.D. Freeman, D.R. Paul, J.E. McGrath, and S. Swinnea, Gas sorption and characterization of thermally rearranged polyimides based on 3,3'-dihydroxy-4,4'-diamino-biphenyl (HAB) and 2,2'-bis-(3,4-dicarboxyphenyl) hexafluoropropane dianhydride (6FDA). Journal of Membrane Science, 2012. 416, 558-567.

17. Aitken, C.L., J.S. McHattie, and D.R. Paul, Dynamic mechanical-behavior of polysulfones. Macromolecules, 1992. 25(11), 2910-2922.

18. Espeso, J., A.E. Lozano, J.G. de la Campa, and J. de Abajo, Effect of substituents on the permeation properties of polyamide membranes. Journal of Membrane Science, 2006. 280(1-2), 659-665.

19. Comer, A.C., C.P. Ribeiro, B.D. Freeman, S. Kalakkunnath, and D.S. Kalika, Dynamic relaxation characteristics of thermally rearranged aromatic polyimides. Polymer, 2013. 54(2), 891-900.

20. Ribeiro, C.P., B.D. Freeman, D.S. Kalika, and S. Kalakkunnath, Aromatic polyimide and polybenzoxazole membranes for the fractionation of aromatic/aliphatic hydrocarbons by pervaporation. Journal of Membrane Science, 2012. 390-391, 182-193.

21. Han, S., H. Kwon, K. Kim, J. Seong, C. Park, S. Kim, C.M. Doherty, A. Thornton, A.J. Hill, A. Lozano, K. Berchtold, and Y. Lee, Tuning microcavities in thermally rearranged polymer membranes for $\mathrm{CO}_{2}$ capture. Physical Chemistry Chemical Physics, 2012. 14(13), 4365-4373.

22. Kim, S. and Y. Lee, Thermally rearranged (TR) polymer membranes with nanoengineered cavities tuned for $\mathrm{CO}_{2}$ separation. Journal of Nanoparticle Research, 2012. 14(7), 1-11.

23. Wang, H., T.-S. Chung, and D.R. Paul, Physical aging and plasticization of thick and thin films of the thermally rearranged ortho-functional polyimide 6FDA$H A B$. Journal of Membrane Science, 2014. 458, 27-35.

24. Wang, H., T.-S. Chung, and D.R. Paul, Thickness dependent thermal rearrangement of an ortho-functional polyimide. Journal of Membrane Science, 2014. 450, 308-312. 
25. Bos, A., I.G.M. Punt, M. Wessling, and H. Strathmann, CO-induced plasticization phenomena in glassy polymers. Journal of Membrane Science, 1999. 155(1), 67-78.

26. Staudt-Bickel, C. and W.J. Koros, Olefin/paraffin gas separations with 6FDAbased polyimide membranes. Journal of Membrane Science, 2000. 170(2), 205214.

27. Staudt-Bickel, C. and W.J. Koros, Improvement of $\mathrm{CO}_{2} / \mathrm{CH}_{4}$ separation characteristics of polyimides by chemical crosslinking. Journal of Membrane Science, 1999. 155(1), 145-154.

28. Wind, J.D., C. Staudt-Bickel, D.R. Paul, and W.J. Koros, The effects of crosslinking chemistry on $\mathrm{CO}_{2}$ plasticization of polyimide gas separation membranes. Industrial \& Engineering Chemistry Research, 2002. 41(24), 61396148.

29. Wind, J.D., D.R. Paul, and W.J. Koros, Natural gas permeation in polyimide membranes. Journal of Membrane Science, 2004. 228(2), 227-236.

30. Kita, H., T. Inada, K. Tanaka, and K.-i. Okamoto, Effect of photocrosslinking on permeability and permselectivity of gases through benzophenone-containing polyimide. Journal of Membrane Science, 1994. 87(1-2), 139-147.

31. McCaig, M.S. and D.R. Paul, Effect of UV crosslinking and physical aging on the gas permeability of thin glassy polyarylate films. Polymer, 1999. 40(26), 72097225.

32. Gleason, K.L., Z.P. Smith, Q. Liu, D.R. Paul, and B.D. Freeman, Pure- and mixed-gas permeation of $\mathrm{CO}_{2}$ and $\mathrm{CH}_{4}$ in thermally rearranged polymers based on 3,3'-dihydroxy-4,4'-diamino-biphenyl (HAB) and 2,2'-bis-(3,4dicarboxyphenyl) hexafluoropropane dianhydride (6FDA). Journal of Membrane Science, 2015. 475, 204-214.

33. Burns, R.L. and W.J. Koros, Defining the challenges for $\mathrm{C}_{3} \mathrm{H}_{6} / \mathrm{C}_{3} \mathrm{H}_{8}$ separation using polymeric membranes. Journal of Membrane Science, 2003. 211(2), 299309.

34. Tanaka, K., A. Taguchi, J. Hao, H. Kita, and K. Okamoto, Permeation and separation properties of polyimide membranes to olefins and paraffins. Journal of Membrane Science, 1996. 121(2), 197-207. 
35. Smith, Z.P., R.R. Tiwari, T.M. Murphy, D.F. Sanders, K.L. Gleason, D.R. Paul, and B.D. Freeman, Hydrogen sorption in polymers for membrane applications. Polymer, 2013. 54(12), 3026-3037.

36. Smith, Z.P., K. Czenkusch, S. Wi, K.L. Gleason, G. Hernández, C.M. Doherty, K. Konstas, T.J. Bastow, C. Álvarez, A.J. Hill, A.E. Lozano, D.R. Paul, and B.D. Freeman, Investigation of the chemical and morphological structure of thermally rearranged polymers. Polymer, 2014. 55(26), 6649-6657.

37. Ghosh, M.K. and K.L. Mital, Polyimides: Fundamentals and applications. 1996, New York, Marcel.

38. Ohya, H., V.V. Kudryavtsev, and S.I. Semenova, Polyimide membranes: Applications, fabrications, and properties. 1996, Amsterdam, Gordon and Breach Publishers.

39. Lin, H. and B.D. Freeman, Springer handbook: Permeation and diffusion, H. Czichos, T. Saito, and L. Smith, Editors. 2006, Springer: New York. 371-387.

40. Smith, Z.P., R.R. Tiwari, M.E. Dose, K.L. Gleason, T.M. Murphy, D.F. Sanders, G. Gunawan, L.M. Robeson, D.R. Paul, and B.D. Freeman, Influence of diffusivity and sorption on helium and hydrogen separations in hydrocarbon, silicon, and fluorocarbon-based polymers. Macromolecules, 2014. 47(9), 3170-3184.

41. Dymond, J.H., K.N. Marsh, R.C. Wilhoit, and K.C. Wong, eds. The virial coefficients of pure gases and mixtures. ed. M. Frenkel and K.N. Marsh. Vol. Group IV: Physical chemistry vol 21 subvolumes A and B. 2001, LandoltBornstein: Berlin.

42. Lemmon, E.W., M.L. Huber, and M.O. McLinden, NIST Standard Reference Database 23. Reference Fluid Thermodynamic and Transport Properties (REFPROP), 2007.

43. Merkel, T.C., V. Bondar, K. Nagai, and B.D. Freeman, Sorption and transport of hydrocarbon and perfluorocarbon gases in poly(1-trimethylsilyl-1-propyne). Journal of Polymer Science Part B: Polymer Physics, 2000. 38(2), 273-296.

44. Kansy, J., Microcomputer program for analysis of positron annihilation lifetime spectra. Nuclear Instruments and Methods in Physics Research Section A: Accelerators, Spectrometers, Detectors and Associated Equipment, 1996. 374(2), 235-244. 
45. Pascual-Izarra, C., A.W. Dong, S.J. Pas, A.J. Hill, B.J. Boyd, and C.J. Drummond, Advanced fitting algorithms for analysing positron annihilation lifetime spectra. Nuclear Instruments and Methods in Physics Research Section A: Accelerators, Spectrometers, Detectors and Associated Equipment, 2009. 603(3), 456-466.

46. Shantarovich, V.P., T. Suzuki, C. He, and V.W. Gustov, Inhibition of positronium formation by polar groups in polymers-relation with TSL experiments. Radiation Physics and Chemistry, 2003. 67(1), 15-23.

47. Jean, Y., P. Mallon, and D. Schrader, Principles and applications of positron \& positronium chemistry. 2003, Singapore, World Scientific.

48. Nakanishi, H., S. Wang, Y. Jean, and S. Sharma, Positron annihilation studies of fluids. World Science, Singapore, 1988, 292.

49. Eldrup, M., D. Lightbody, and J.N. Sherwood, The temperature dependence of positron lifetimes in solid pivalic acid. Chemical Physics, 1981. 63(1-2), 51-58.

50. Tao, S.J., Positronium annihilation in molecular substances. The Journal of Chemical Physics, 1972. 56(11), 5499-5510.

51. Hill, A.J., Positron annihilation lifetime spectroscopy, in Polymer characterization techniques and their applications to blends, G.P. Simon, Editor. 2003, Oxford University Press: Washington, D.C. 401-435.

52. Xie, W., H. Ju, G.M. Geise, B.D. Freeman, J.I. Mardel, A.J. Hill, and J.E. McGrath, Effect of free volume on water and salt transport properties in directly copolymerized disulfonated poly(arylene ether sulfone) random copolymers. Macromolecules, 2011. 44(11), 4428-4438.

53. Hirayama, Y., T. Yoshinaga, Y. Kusuki, K. Ninomiya, T. Sakakibara, and T. Tamari, Relation of gas permeability with structure of aromatic polyimides II. Journal of Membrane Science, 1996. 111(2), 183-192.

54. Calle, M., A.E. Lozano, and Y.M. Lee, Formation of thermally rearranged (TR) polybenzoxazoles: Effect of synthesis routes and polymer form. European Polymer Journal, 2012. 48(7), 1313-1322.

55. Tullos, G. and L. Mathias, Unexpected thermal conversion of hydroxy-containing polyimides to polybenzoxazoles. Polymer, 1999. 40(12), 3463-3468. 
56. Tullos, G.L., J.M. Powers, S.J. Jeskey, and L.J. Mathias, Thermal conversion of hydroxy-containing imides to benzoxazoles: Polymer and model compound study. Macromolecules, 1999. 32(11), 3598-3612.

57. Choi, J.I., C.H. Jung, S.H. Han, H.B. Park, and Y.M. Lee, Thermally rearranged (TR) poly(benzoxazole-co-pyrrolone) membranes tuned for high gas permeability and selectivity. Journal of Membrane Science, 2010. 349(1-2), 358-368.

58. Han, S.H., J.E. Lee, K.-J. Lee, H.B. Park, and Y.M. Lee, Highly gas permeable and microporous polybenzimidazole membrane by thermal rearrangement. Journal of Membrane Science, 2010. 357(1-2), 143-151.

59. Jung, C.H., J.E. Lee, S.H. Han, H.B. Park, and Y.M. Lee, Highly permeable and selective poly(benzoxazole-co-imide) membranes for gas separation. Journal of Membrane Science, 2010. 350(1-2), 301-309.

60. Li, S., H.J. Jo, S.H. Han, C.H. Park, S. Kim, P.M. Budd, and Y.M. Lee, Mechanically robust thermally rearranged (TR) polymer membranes with spirobisindane for gas separation. Journal of Membrane Science, 2013. 434, 137147.

61. Wang, H., D.R. Paul, and T.-S. Chung, The effect of purge environment on thermal rearrangement of ortho-functional polyamide and polyimide. Polymer, 2013. 54(9), 2324-2334.

62. Muñoz, D.M., M. Calle, J.G. de la Campa, J. de Abajo, and A.E. Lozano, An improved method for preparing very high molecular weight polyimides. Macromolecules, 2009. 42(15), 5892-5894.

63. Ando, S., T. Matsuura, and S. Sasaki, Coloration of aromatic polyimides and electronic properties of their source materials. Polymer Journal, 1997. 29(1), 6976.

64. Robeson, L.M., The upper bound revisited. Journal of Membrane Science, 2008. 320(1-2), 390-400.

65. Wang, H., S. Liu, T.-S. Chung, H. Chen, Y.-C. Jean, and K.P. Pramoda, The evolution of poly(hydroxyamide amic acid) to poly(benzoxazole) via stepwise thermal cyclization: Structural changes and gas transport properties. Polymer, 2011. 52(22), 5127-5138. 
66. Scholes, C.A., C.P. Ribeiro, S.E. Kentish, and B.D. Freeman, Thermal rearranged poly(benzoxazole-co-imide) membranes for $\mathrm{CO}_{2}$ separation. Journal of Membrane Science, 2014. 450, 72-80.

67. Kim, S. and Y.M. Lee, Rigid and microporous polymers for gas separation membranes. Progress in Polymer Science, 2015. 43(0), 1-32.

68. Jiang, Y., F.T. Willmore, D. Sanders, Z.P. Smith, C.P. Ribeiro, C.M. Doherty, A. Thornton, A.J. Hill, B.D. Freeman, and I.C. Sanchez, Cavity size, sorption and transport characteristics of thermally rearranged (TR) polymers. Polymer, 2011. 52(10), 2244-2254.

69. Park, C.H., E. Tocci, Y.M. Lee, and E. Drioli, Thermal treatment effect on the structure and property change between hydroxy-containing polyimides (HPIs) and thermally rearranged polybenzoxazole (TR-PBO). The Journal of Physical Chemistry B, 2012. 116(42), 12864-12877.

70. Shimazu, A., T. Miyazaki, M. Maeda, and K. Ikeda, Relationships between the chemical structures and the solubility, diffusivity, and permselectivity of propylene and propane in 6FDA-based polyimides. Journal of Polymer Science Part B: Polymer Physics, 2000. 38(19), 2525-2536.

71. Puleo, A.C., D.R. Paul, and S.S. Kelley, The effect of degree of acetylation on gas sorption and transport behavior in cellulose acetate. Journal of Membrane Science, 1989. 47(3), 301-332.

72. Ismail, A.F. and W. Lorna, Penetrant-induced plasticization phenomenon in glassy polymers for gas separation membrane. Separation and Purification Technology, 2002. 27(3), 173-194.

73. Wonders, A.G. and D.R. Paul, Effect of $\mathrm{CO}_{2}$ exposure history on sorption and transport in polycarbonate. Journal of Membrane Science, 1979. 5(0), 63-75.

74. Bos, A., I.G.M. Pünt, M. Wessling, and H. Strathmann, Plasticization-resistant glassy polyimide membranes for $\mathrm{CO}_{2} / \mathrm{CO}_{4}$ separations. Separation and Purification Technology, 1998. 14(1-3), 27-39.

75. Wessling, M., I. Huisman, T.v.d. Boomgaard, and C.A. Smolders, Timedependent permeation of carbon dioxide through a polyimide membrane above the plasticization pressure. Journal of Applied Polymer Science, 1995. 58(11), 1959-1966. 
76. Wind, J.D., C. Staudt-Bickel, D.R. Paul, and W.J. Koros, Solid-state covalent cross-linking of polyimide membranes for carbon dioxide plasticization reduction. Macromolecules, 2003. 36(6), 1882-1888.

77. Matteucci, S.T., Y.P. Yampolskii, B.D. Freeman, and I. Pinnau, Transport of gases and vapors in glassy and rubbery polymers, in Materials science of membranes for gas and vapor separation, Y. Yampolskii, I. Pinnau, and B.D. Freeman, Editors. 2006, John Wiley \& Sons: Chichester. 1-47.

78. Poling, B.E., J.M. Prausnitz, and J.P. O'Connell, The properties of gases and liquids. 2001, McGraw Hill Book Co., New York, NY. A.5-A.19.

79. Bevington, P.R. and K.D. Robinson, Data reduction and error analysis for the physical sciences: Third edition. 2003, Boston, McGraw Hill.

80. Rungta, M., C. Zhang, W.J. Koros, and L. Xu, Membrane-based ethylene/ethane separation: The upper bound and beyond. AIChE Journal, 2013. 59(9), 34753489. 